\title{
The Overall Malmquist Index: A New Approach for Measuring Productivity Changes Over Time
}

\author{
Mohsen Afsharian ${ }^{1}$ and Heinz Ahn ${ }^{2}$ \\ Department of Business Sciences, Technische Universität Braunschweig, Fallersleber-Tor-Wall 23, 38100 \\ Braunschweig, Germany
}

\begin{abstract}
This paper deals with a special case of the non-homogeneity problem related to the determination of the global benchmark technology when measuring productivity changes over time. The authors propose a new way of constructing the global framework of the Malmquist index which applies the minimum extrapolation principle on the aggregation of the experienced contemporaneous technologies. The proposed index, called overall Malmquist index, preserves the role of each contemporaneous technology in the determination of the newly-proposed best practice technology, whereby an acceptable level of discrimination between non-homogeneous observations is provided. With respect to both computational and test properties, the proposed index possesses the circularity property, generates a single measure of productivity change and is immune to infeasibility under variable returns to scale. Furthermore, unlike in the global form, previously computed results by the overall Malmquist index are more stable and less sensitive to changes in the shape of the best practice technology when a new time period is incorporated. Similar to traditional indices, it can be decomposed into various components such as efficiency change, scale efficiency change, and best practice change. The suggested index will be illustrated by means of a real-world example from banking. In particular, it will be compared to the contemporaneous and global forms of the Malmquist index introduced into the literature by Färe et al. (1992) and Pastor and Lovell (2005), respectively.
\end{abstract}

Keywords Data Envelopment Analysis (DEA), productivity measurement, Malmquist productivity index, overall Malmquist index, banking

JEL Classification C44, C67, D24

\section{Table of Contents}

1 Introduction 1

2 Literature Review 2

3 The Contemporaneous and Global Malmquist Indices 6

4 The Overall Malmquist Index 9

5 Formalization of the Overall Malmquist Index 13

6 Illustrative Numerical Example $\quad 20$

7 Conclusions and Outlook on Future Research 24

\footnotetext{
${ }^{1}$ Email: m.afsharian@tu-bs.de; Phone: +495313913606; Fax: +495313918121 (corresponding author)

${ }^{2}$ Email: hw.ahn@tu-bs.de
} 


\section{Introduction}

The Malmquist index is among the most important indices for measuring productivity changes of decision making units (DMUs) over time. It has been applied successfully in various environments such as the health sector (e.g., see Kirigia et al. 2007; Chowdhury et al. 2011), the electricity industry (e.g., see Tovar et al. 2011; Aghdam 2011), telecommunications (e.g., see Lam and Shiu 2010; Hisali and Yawe 2011), the water industry (e.g., see Corton and Berg 2009; Portela et al. 2011), agriculture (e.g., see Kao 2010; Xu 2012), transportation (e.g., see Gitto and Mancuso 2012; Pires and Fernandes 2012), the banking industry (e.g., see Asmild et al. 2004; Portela and Thanassoulis 2010), and others.

The first Malmquist-type productivity index has been introduced into the literature by Caves et al. (1982). They extended the idea of Malmquist (1953), who proposed to construct quantity indices as ratios of distance functions in the context of consumption analysis. Färe et al. (1992) adapted the work of Caves et al. (1982) to the non-parametric approach. They showed how Data Envelopment Analysis (DEA), proposed by Farrell (1957) and developed by Charnes et al. (1978), can be used for measuring productivity changes over time. After this seminal work, there have been a great number of studies about the framework, decomposition and computation of the Malmquist index.

Among the different frameworks that define the characteristics of the benchmark technology, the global framework to measure the productivity changes proposed by Pastor and Lovell (2005) has recently begun to receive considerable attention by researchers (see, e.g., Portela and Thanassoulis 2008; Oh 2010; Oh and Lee 2010; Wang et al. 2012). It considers a single global technology constructed from all data for all observations and all time periods, which not only makes the measurement much simpler compared to previously-proposed methods but also provides a number of attractive features (see Pastor and Lovell 2005). However, this is achieved at the cost of being dependent upon a convex envelope of all experienced technologies (i.e. contemporaneous technologies), whereby 1) the role of each contemporaneous technology in the determination of the global benchmark technology is neglected, i.e. crucial information might get lost; 2) convex combinations of observations across time periods have to be considered feasible, i.e. it may not provide sufficient discrimination between non-homogeneous observations across time periods; 3 ) previously computed results by the global Malmquist index can change significantly when a new time period is incorporated, i.e. the index may be very sensitive to alterations in the shape of the global benchmark technology.

One may find this problematic, especially over a study horizon which is characterized by rapid technological change, changes in government rules and regulations, new policy directives, or shifts in the competitive situation and economic conditions. Under such circumstances, the convex envelope of all experienced technologies as a global best practice technology is unrealistic or even irritating, i.e. a particular case of non-homogeneity problem occurs. Hence, this paper proposes a new Malmquist-type 
index, the so-called overall Malmquist index, which is capable to overcome the outlined type of the non-homogeneity problem related to the determination of the global benchmark technology when measuring productivity changes over time.

The outline of the paper is as follows: In Section 2, the state of the art will be reviewed covering the framework, decomposition, and computation of the Malmquist productivity index. Section 3 presents a brief overview of the DEA-based Malmquist index in both the contemporaneous and global forms. Section 4 introduces and illustrates the idea of the new Malmquist-type index and compares it with the global Malmquist index. The theoretical aspects of the proposed index will be described in Section 5 . In Section 6, the suggested index and its advantages will be studied on the basis of a real-world example from banking. The paper concludes with a summary and an outlook on future research opportunities in Section 7.

\section{Literature Review}

Caves et al. (1982) introduced the earliest type of the Malmquist index and showed how the change in productivity experienced by an operating unit can be measured over time. The index has been named after Malmquist (1953), who proposed to construct quantity indices as ratios of distance functions in the context of consumption analysis. Nishimizu and Page (1982) identified technological change (henceforth abbreviated as: technical change) and changes in technical efficiency as two components of productivity change over time. Then, Färe et al. (1992) used DEA as mathematical programmingbased methodology to measure the Malmquist productivity index. In the same paper, they also described how the Malmquist index can be decomposed into technical change and technical efficiency change (i.e. FGLR decomposition of the Malmquist index). After this seminal work, there have been a considerable number of studies in the literature about the framework, decomposition, and computation of the Malmquist index.

The so-called contemporaneous Malmquist index proposed by Färe et al. (1992) applies the geometric mean of two measures of productivity change, which refer to the adjacent time periods under consideration. Consequently, it provides a measure of productivity change, which fails circularity, i.e. the change in productivity between time periods $t$ and $t+2$ may not be derived even when the change in productivity between two adjacent time periods $t$ and $t+1$ as well as between time periods $t+1$ and $t+2$ are known. Infeasibilities can also occur when mathematical programming techniques are used to compute and decompose the index under variable returns to scale (VRS) assumption for the benchmark technologies (see, e.g., Ray and Desli 1997).

Accordingly, over the last decade, there has been an extensive focus on the methodological development of the Malmquist index. Berg et al. (1992) offered an approach to determine the Malmquist index that compares adjacent periods by means of a benchmark technology related to the 
base period. This index satisfies circularity and generates a single measure of productivity change, but on the other hand it is base period dependent and unable to overcome the infeasibility problem. Shestalova (2003) suggested an alternative way to measure the geometric version of the Malmquist index that uses sequential benchmark technologies. In this framework, a sequential technology is formed from convex aggregation of observations in all periods up to the period under consideration. The Malmquist index computed by this approach generates a single measure of productivity change and is immune to the infeasibility issue, but it fails circularity and precludes technical regress.

In the following, Pastor and Lovell (2005) proposed a global best practice technology, which is obtained by a convex union of all contemporaneous technologies, i.e. it covers all observations from all contemporaneous technologies. The authors showed that this index generates a single value of productivity change, possesses the circularity property, allows technical regress and avoids infeasibilities under VRS. However, a computational drawback of their global Malmquist index is that since it is calculated from all observations from all time periods, it must be recomputed when a new time period is experienced. This problem has been studied by Pastor et al. (2011). The authors suggested a biennial benchmark technology, which is defined as the convex combination of observations of the two adjacent time periods under consideration. On this basis, their proposed biennial Malmquist productivity index does not need to be recomputed when a new time period is added to the data set, but this is achieved with the loss of the circularity property.

With respect to the decomposition of the Malmquist index, Färe et al. (1992) assumed that the benchmark technology exhibits constant returns to scale (CRS) and introduced the well-known twoway decomposition of the Malmquist index, namely FGLR. It was developed further to provide a clearer picture of the root sources of productivity change by alternative decompositions of the Malmquist index. Färe et al. (1994) considered VRS and offered a three-way decomposition of the Malmquist index with another important factor, which can capture the change in scale efficiency (i.e. FGNZ decomposition). More precisely, they used CRS as a basic assumption for the benchmark technology and also added VRS technology to measure the scale efficiency change experienced by a unit between two periods. Ray and Desli (1997) questioned the validity of applying both CRS and VRS at the same time in FGNZ decomposition. The authors believed that CRS can be a strong assumption about the underlying benchmark technology, and when CRS does not hold, this decomposition might be meaningless. Accordingly, they suggested another alternative three-way decomposition that measures technical change based on VRS-based benchmark technology (i.e. RD decomposition). In the same paper, the authors showed that their proposed method not only offers a different measure for the technical change component but also that it comprises a different interpretation about the scale efficiency change component.

In an effort to generate elaborate components and a simple intuitive interpretation corresponding to the components, there have been a number of expanded decompositions of the Malmquist index. For 
instance, Simar and Wilson (1998) and Zofio and Lovell (1998) proposed a four-way decomposition of the Malmquist index whose technical and scale efficiency change components are retained from the corresponding components from RD and FGNZ decompositions, respectively. This decomposition has also been considered in Gilbert and Wilson (1998), Wheelock and Wilson (1999) and Grifell-Tatjé and Lovell (1999). Zofio (2007) proposed an even more elaborate and comprehensive decomposition of the Malmquist index. The decomposition not only includes all the highly accepted components in the literature (e.g. components in RD and FGNZ) in a unifying framework, but also gives a more clear and accurate interpretation of them. More recently, Alirezaee and Afsharian (2010) showed that the result of the Malmquist index might change in the presence of some additional rules and regulations, which can be imposed to the benchmark technology by means of weight restrictions or trade-offs. They offered another four-way decomposition of the Malmquist index incorporating a new component representing the contribution of changes in regulation efficiency. A more thorough review of different decompositions can be found in Lovell (2003) and Grosskopf (2003).

For the computational development of the Malmquist index, a number of ways have been suggested in the literature. Färe et al. $(1992,1994)$ utilized the input and output radial DEA models to compute the Malmquist productivity index. The radial models suffer from neglecting of slacks and do not consider decision maker's preferences over performance improvement of individual inputs or outputs. Therefore, non-radial DEA models have been proposed in order to overcome the aforementioned limitations of the previously-proposed methods. Examples are the Malmquist index which applies slack-based distance functions developed by Chen (2003), the hyperbolic Malmquist index by Zofio and Lovell (2001) which uses hyperbolic distance functions, as well as the quasi-Malmquist index proposed by Grifell-Tatjé et al. (1998) in which quasi-distance functions are applied. Furthermore, when some outputs are undesirable, Chung et al. (1997) applied the directional distance function proposed by Chambers et al. (1998) and offered a Malmquist-Luenberger indicator, which can measure environmentally sensitive productivity growth (see also Aparicio et al. 2013). A particular type of the directional distance function introduced by Portela et al. (2004) - the so-called range directional model - has also been used in order to measure productivity changes under negative data in Portela and Thanassoulis (2010).

The non-homogeneity problem in measuring the Malmquist productivity indices has been recently considered by relatively few authors. Camanho and Dyson (2006) presented a modified version of the contemporaneous Malmquist index for comparing groups of observations operating in different programs or environments. Their index no longer measures the productivity change between two time periods, but provides a cross-sectional comparison of the performance of groups of homogeneous DMUs in a static setting. Battese et al. (2004) proposed a meta-frontier approach in the area of a parametric productivity analysis for the estimation of technical efficiencies and technology gaps for observations that may not have the same technology (for a detailed review of the meta-frontier approach, see, e.g., Hayami 1969; Hayami and Ruttan 1970). Their approach assumes that there are 
several well-defined groups of homogeneous observations for the same industry, i.e. observations are classified into homogeneous groups by some factors such as location, size, process, etc. Accordingly, local frontiers are constructed by considering the convex union of all observations belonging to the same group while the meta-frontier is the convex envelope of the group frontiers. It has to be noted that the definition of the meta-frontier is equivalent to the global frontier proposed by Pastor and Lovell (2005).

The idea of the meta-frontier approach has been revisited in the field of non-parametric productivity analysis by Portela and Thanassoulis (2008). The authors showed how their meta-Malmquist index can be used for the measurement of the productivity growth of DMUs in the presence of negative data. An extended meta-Malmquist index has been introduced by $\mathrm{Oh}$ and Lee (2010). In addition to the contemporaneous and global benchmark technologies, they applied the so-called inter-temporal benchmark technology by which the convex union of some contemporaneous technologies is considered in the analysis. Asmild et al. (2004) suggested a combination of the window analysis (Charnes et al. 1985) and the Malmquist index in order to enlarge the quantity of observations which operates under the same technology. They also showed how the number of actual time periods with an inter-temporal manner included in the analysis can be controlled by a predetermined setting of the window width. Consequently, one may also produce the inter-temporal and global benchmark technologies by setting appropriate values for the window widths within the framework of Asmild et al. (2004).

A review of the studies leads to the conclusion that in the global framework of the Malmquist index DMUs are assumed to be potentially able to access a single best practice technology, which is obtained by the convex hull of all contemporaneous technologies. Accordingly, convex combinations of observations across time periods (as virtual production units) have to be considered producible and hence feasible. However, in many cases observations belonging to different time periods may have little or nothing in common because of rapid technological changes or significant changes in government rules and regulations, policy directives, the competitive situation and economic conditions, etc. In these cases, convex combinations of such observations may not be feasible and hence corresponding productivity measures might be biased and cannot be used for improving performance. Furthermore, the convex envelope of all experienced technologies, which may have different characteristics, neglects the role of each contemporaneous technology to determine the global benchmark technology. In other words, a global convex set, which is formed from data of all observations in all periods, may not provide sufficient discrimination between non-homogeneous observations in the determination of the global efficient frontier; crucial information might get lost taking this type of best practice technology.

We therefore propose an alternative Malmquist-type index, the overall Malmquist index, which deals with cases in which the above-described aggregation of contemporaneous technologies would not 
provide a valid measure. The new index possesses the circularity property, generates a single measure of productivity change and is immune to infeasibility under VRS. In addition, unlike in the global form, the overall Malmquist index is more stable and less sensitive to changes in the shape of the benchmark technology when a new time period is incorporated. Similar to traditional indices, it can be decomposed into various components such as efficiency change, scale efficiency change, and best practice change.

\section{The Contemporaneous and Global Malmquist Indices}

Suppose that there exist $n$ DMUs in $t$ time periods $(t=1, \ldots, T)$. Let $X_{j}^{t}=\left(x_{1 j}^{t}, x_{2 j}^{t}, \ldots, x_{m j}^{t}\right)$ and $Y_{j}^{t}=\left(y_{1 j}^{t}, y_{2 j}^{t}, \ldots, y_{s j}^{t}\right)$ be non-negative and non-zero vectors, which quantify the level of inputs and outputs of $\mathrm{DMU}_{j}, j=1, \ldots, n$, in contemporaneous period $t,(t=1, \ldots, T)$. We assume that all DMUs in each time period $t$ operate under the same technology, e.g., resulting from the same environment as well as the same competitive situation, economic conditions, etc. It is also assumed that the technology remains unaltered between the start and the end of $t$. Hence, each contemporaneous technology in time period $t$ can be represented by a production possibility set (PPS) or technology set (in the following also abbreviated as "technology") of feasible input-output combinations as follows:

$$
P P S^{t}=\left\{\left(X^{t}, Y^{t}\right) \in \mathfrak{R}_{+}^{m} \times \mathfrak{R}_{+}^{s} \mid X^{t} \text { can produce } Y^{t}\right\} \quad t=1, \ldots, T
$$

In terms of properties satisfied by each contemporaneous period $t, P P S^{t}$ can be characterized precisely by applying desired mathematical axioms such as non-emptiness, free disposability, ray unboundedness, convexity, feasibility of trade-offs and minimum extrapolation, etc. (see, e.g., Charnes et al. 1978; Banker et al. 1984; Podinovski 2004). Different types of the Malmquist index have also been applied on varying technologies which can be characterized by means of different sets of abovementioned axioms. Examples are the Malmquist indices applying on free disposal hull (FDH) technologies (see, e.g., Tulkens and Malnero 1994), standard convex technologies under different returns to scales (see, e.g., Färe et al. 1992), and more recent technologies that are able to add value judgments to the standard technologies by incorporating production trade-offs (see, e.g., Alirezaee and Afsharian 2010). Throughout the paper, without loss of generality (following, e.g., Färe et al. 1992; Pastor and Lovell 2005), we assume that contemporaneous production possibility sets satisfy nonemptiness, free disposability, convexity, ray unboundedness or CRS and minimum extrapolation. Nonetheless, the analysis may be straightforwardly extended to other types of technologies. On this basis, the contemporaneous technologies can be expressed precisely by means of the following sets (Charnes et al. 1978): 


$$
P P S_{C R S}^{t}=\left\{\left(X^{t}, Y^{t}\right) \in \mathfrak{R}_{+}^{m} \times \mathfrak{R}_{+}^{s} \mid X^{t} \geq \sum_{j=1}^{n} \lambda_{j}^{t} x_{i j}^{t}, \quad Y^{t} \leq \sum_{j=1}^{n} \lambda_{j}^{t} y_{r j}^{t} ; \quad \lambda_{j}^{t} \geq 0 ; \quad j=1, \ldots, n\right\} \quad t=1, \ldots, T
$$

where the subscript "CRS" indicates that the production possibility sets satisfy constant returns to scale. Subsequently, the contemporaneous Malmquist index for $\operatorname{DMU}_{p}(p=1, \ldots, n)$ between two time periods $t$ and $t+1$ is defined as:

$$
\begin{aligned}
M_{C R S}\left(X_{p}^{t+1}, Y_{p}^{t+1}, X_{p}^{t}, Y_{p}^{t}\right) & =\left[M I_{C R S}^{t+1}\left(X_{p}^{t+1}, Y_{p}^{t+1}, X_{p}^{t}, Y_{p}^{t}\right) \times M I_{C R S}^{t}\left(X_{p}^{t+1}, Y_{p}^{t+1}, X_{p}^{t}, Y_{p}^{t}\right)\right]^{\frac{1}{2}} \\
& =\left[\frac{B_{C R S}^{6+1}\left(X_{p}^{t+1}, Y_{p}^{t+1}\right)}{D_{C R S}^{6+1}\left(X_{p}^{t}, Y_{p}^{t}\right)} \times \frac{B_{C R S}^{6}\left(X_{p}^{t+1}, Y_{p}^{t+1}\right)}{D_{C R S}^{6}\left(X_{p}^{t}, Y_{p}^{t}\right)}\right]^{\frac{1}{2}}
\end{aligned}
$$

where $M I$ is determined as the geometric mean of $M I^{t+1}$ and $M I^{t}$. In addition, the output distance functions can be defined as follows (Shephard 1970):

$$
B_{C R S}^{6}\left(X^{l}, Y^{l}\right)=\inf \left\{\beta:\left(X^{l}, Y^{l} / \beta\right) \in P P S_{C R S}^{k}\right\} X^{l} \in R_{+}^{m}, \quad Y^{l} \in R_{+}^{s}, \quad l, k=t, t+1
$$

Given $X^{l}$, vector $Y^{l}$ increases as much as possible by scaling it by $\beta$ while remaining in a corresponding PPS. Note that (4) defines an output distance function, but the definition of an input distance function can be done similarly (see, e.g., Fried et al. 2008). Furthermore, the contemporaneous Malmquist index can be exhibited by the multiplication of the following components (for a more detailed review of the contemporaneous Malmquist index and its decompositions, see Färe et al. 1992):

Efficiency Change (EC) $=\frac{T E_{C R S}^{t+1}\left(X_{p}^{t+1}, Y_{p}^{t+1}\right)}{T E_{C R S}^{t}\left(X_{p}^{t}, Y_{p}^{t}\right)}=\frac{B_{C R S}^{t+1}\left(X_{p}^{t+1}, Y_{p}^{t+1}\right)}{B_{C R S}^{6}\left(X_{p}^{t}, Y_{p}^{t}\right)}$

Technical Change $(\mathrm{TC})=\left[T G_{C R S}^{t, t+1}\left(X_{p}^{t}, Y_{p}^{t}\right) \times T G_{C R S}^{t, t+1}\left(X_{p}^{t+1}, Y_{p}^{t+1}\right)\right]^{\frac{1}{2}}$

$$
=\left[\frac{B_{C R S}^{6}\left(X_{p}^{t}, Y_{p}^{t}\right)}{B_{C R S}^{6+1}\left(X_{p}^{t}, Y_{p}^{t}\right)} \times \frac{B_{C R S}^{6}\left(X_{p}^{t+1}, Y_{p}^{t+1}\right)}{B_{C R S}^{6+1}\left(X_{p}^{t+1}, Y_{p}^{t+1}\right)}\right]^{\frac{1}{2}}
$$

With respect to the definition of $P P S_{C R S}^{t}$ in contemporaneous period $t(t=1, \ldots, T)$, the global production possibility set or global technology can be defined as follows (Pastor and Lovell 2005):

$$
P P S_{C R S}^{G}=\text { Convex }\left\{P P S_{C R S}^{1} \cup P P S_{C R S}^{2} \cup \ldots \cup P P S_{C R S}^{T}\right\}
$$

where $P P S_{C R S}^{G}$ is the convex envelope of all the contemporaneous technologies and automatically satisfies all the axioms as the contemporaneous benchmark technologies do. It has to be noted that by using such a global benchmark technology, all observations from all periods are assumed to be 
theoretically and potentially able to access a single best practice technology which is obtained by the convex aggregation of the experienced contemporaneous technologies (see also Oh and Lee 2010; Chen and Yang 2011).

Since there is only one (global) best practice technology, there is no need to resort to the geometric mean convention when defining the global form of the Malmquist index. Hence, the global Malmquist productivity index based on the above global technology is defined by means of the following ratio:

$$
M I_{C R S}^{G}\left(X_{p}^{t+1}, Y_{p}^{t+1}, X_{p}^{t}, Y_{p}^{t}\right)=\frac{B_{C R S}^{6}\left(X_{p}^{t+1}, Y_{p}^{t+1}\right)}{B_{C R S}^{6}\left(X_{p}^{t}, Y_{p}^{t}\right)}
$$

where the distance functions can be determined as follows:

$$
B_{C R S}^{G}\left(X^{t}, Y^{t}\right)=\inf \left\{\beta:\left(X^{t}, Y^{t} / \beta\right) \in P P S_{C R S}^{G}\right\} \quad X^{t} \in R_{+}^{m}, \quad Y^{t} \in R_{+}^{s}, \quad t=1, \ldots, T
$$

Similar to the contemporaneous Malmquist index, the results of the global Malmquist index can be represented by the following decomposition (for a more detailed review of the global Malmquist index and its decompositions, see Pastor and Lovell 2005):

$$
G M I=E C \times B P C
$$

where

$$
\begin{aligned}
\text { Best Practice Change (BPC) } & =\left[\frac{B P G_{C R S}^{G, t+1}\left(X_{p}^{t+1}, Y_{p}^{t+1}\right)}{B P G_{C R S}^{G, t}\left(X_{p}^{t}, Y_{p}^{t}\right)}\right] \\
& =\left[\frac{B_{C R S}^{6}\left(X_{p}^{t+1}, Y_{p}^{t+1}\right)}{B_{C R S}^{t^{+1}}\left(X_{p}^{t+1}, Y_{p}^{t+1}\right)} \times \frac{B_{C R S}^{6}\left(X_{p}^{t}, Y_{p}^{t}\right)}{D_{C R S}^{6}\left(X_{p}^{t}, Y_{p}^{t}\right)}\right]
\end{aligned}
$$

Since $P P S_{C R S}^{G}$ in (7) uses the convex aggregation of the contemporaneous technologies, it can be easily obtained by considering the same axioms as the contemporaneous technologies but this time applying on the set of all observations from all periods (see Portela and Thanassoulis 2008). Accordingly, the contemporaneous and global forms of the Malmquist index as well as the corresponding components can be determined by the following distance functions: $B_{C R S}^{6}\left(X_{p}^{l}, Y_{p}^{l}\right), k, l=t, t+1$ as well as $B_{C R S}^{G}\left(X_{p}^{l}, Y_{p}^{l}\right), \quad l=t, t+1$, which can be computed by means of the linear programming problems as follows: 


$$
\begin{aligned}
& {\left[B_{C R S}^{6}\left(X_{p}^{l}, Y_{p}^{l}\right)\right]^{-1}=} \\
& {\left[B_{C R S}^{G}\left(X_{p}^{l}, Y_{p}^{l}\right)\right]^{-1}=}
\end{aligned}
$$

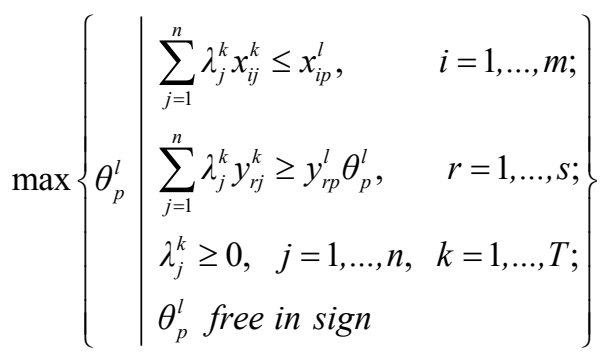

$$
\begin{aligned}
& \max \left\{\begin{array}{l|l}
\theta_{p}^{l} & \begin{array}{ll}
\sum_{k=1}^{T} \sum_{j=1}^{n} \lambda_{j}^{k} x_{i j}^{k} \leq x_{i p}^{l}, & i=1, \ldots, m ; \\
\sum_{k=1}^{T} \sum_{j=1}^{n} \lambda_{j}^{k} y_{r j}^{k} \geq y_{r p}^{l} \theta_{p}^{l}, & r=1, \ldots, s ; \\
\lambda_{j}^{k} \geq 0, \quad j=1, \ldots, n, & k=1, \ldots, T ; \\
\theta_{p}^{l} \text { free in sign }
\end{array}
\end{array}\right\}
\end{aligned}
$$

Comparing the above models, (13) uses the same structure as (12) for the computation of the respective distance functions on the global benchmark technology. This is not surprising since it has implicitly been assumed that the global technology possesses the same characteristics as the contemporaneous benchmark technologies. However, the assumption that all observations from different time periods in the global production possibility set are considered to be homogeneous is questionable, e.g. convex combinations of observations across time periods may not be producible. A further objection is that the role of each contemporaneous technology in the determination of the global benchmark technology as an (best practice) experienced technology, which is a global convex set, is neglected. This can become even more apparent when the axioms, which characterize the structure of the contemporaneous technologies, also change over time, e.g. different value judgments may have been incorporated into the contemporaneous technologies at the time. Against this background, the following section introduces the overall Malmquist index as an alternative approach to measure productivity changes over time.

\section{The Overall Malmquist Index}

In order to illustrate the idea of the overall Malmquist index and comparing it to the global Malmquist index, let us consider the simple case depicted in Figure 1, where there exist four observed units including one input and two outputs in two time periods.

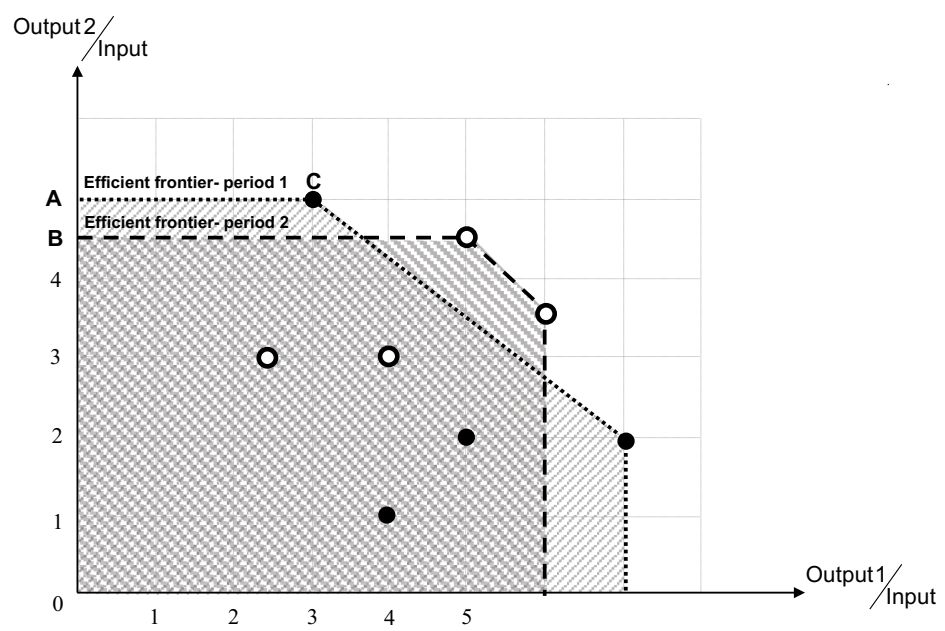

Fig. 1 Two contemporaneous technologies and their efficient frontiers 
Furthermore, let all units have the same level of input in each time period. It is assumed that observations in each time period operate under the same technology. Accordingly, the two technologies are shown in Figure 1 with $P P S_{C R S}^{1}$ and $P P S_{C R S}^{2}$ as the shaded areas bounded by ACGH and BDEF, respectively. The two contemporaneous production possibility sets have been determined by means of the definition given in (2), whereby each contemporaneous technology satisfies free disposability, convexity, ray unboundedness and minimum extrapolation. It has to be noted that by considering convexity in each contemporaneous technology, we stressed on the assumption that the characteristics of the technology remains constant between the start and the end of that time period.

According to (7), in the case of the global benchmark technology, all observations from the two time periods are assumed to be theoretically and potentially able to access a single best practice technology. This is obtained by the convex aggregation (i.e. convex hull) of the experienced contemporaneous technologies as follows:

$$
P P S_{C R S}^{G}=\text { Convex }\left\{P P S_{C R S}^{1} \cup P P S_{C R S}^{2}\right\}
$$

The global technology and the corresponding global efficient frontier are shown in Figure 2.

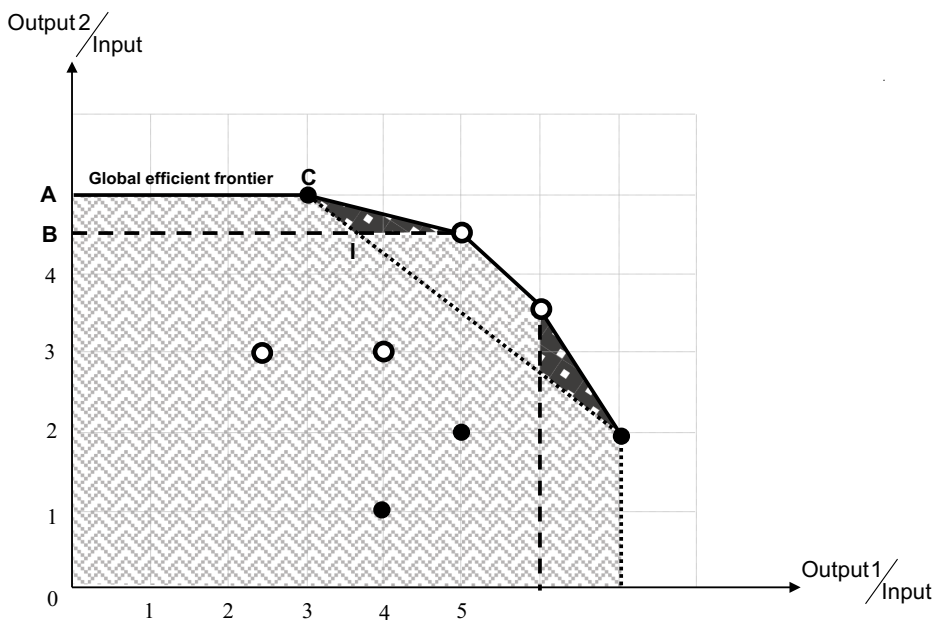

Fig. 2 The global technology and its efficient frontier

As can be seen from this figure, $P P S_{C R S}^{G}$ is the shaded area bounded by ACDEGH. It is noticeable that, e.g., the segment $\mathrm{CD}$, which belongs to the global efficient frontier, is constructed by a convex combination of units $\mathrm{C}$ and $\mathrm{D}$. These units come from different contemporaneous technologies, i.e. technologies 1 and 2. The same applies to the segment EG. That is the result of the assumption that the characteristics of technology remained unchanged over time such that all observations from different time periods are considered to be homogeneous. Accordingly, the convex aggregation of the two contemporaneous technologies is proper to determine the global benchmark technology as a best practice technology which has been experienced over time, i.e. the corresponding global frontier is constructed as convex combinations of the most efficient units over time. 
A direct consequence of this assumption will also add areas to the global technology which are only formed when convexity is applied between observations from the two time periods. In our case, these areas are represented by CDI and EGJ in Figure 2. Note here that assuming convexity between observations within each contemporaneous period is a strong premise (see Podinovski 2005; Portela and Thanassoulis 2008), while there are two distinct technologies which may have different characteristics. More precisely, even if contemporaneous technology sets are assumed to satisfy convexity (resulting from the same environment in each time period) there is no reason why the union of these sets should be convex (as the environment can change over time), i.e. especially when the change in technology is rapid and observations from two periods have little in common. In such situations, the convex combination between observations from the contemporaneous technologies can produce virtual production units which may not be producible in reality. As a consequence, estimated productivity changes, determined on the basis of this type of best practice technology, can be influenced by these virtual units such that the results become unreliable. In order to clarify this case, consider unit 1 depicted in Figure 3.

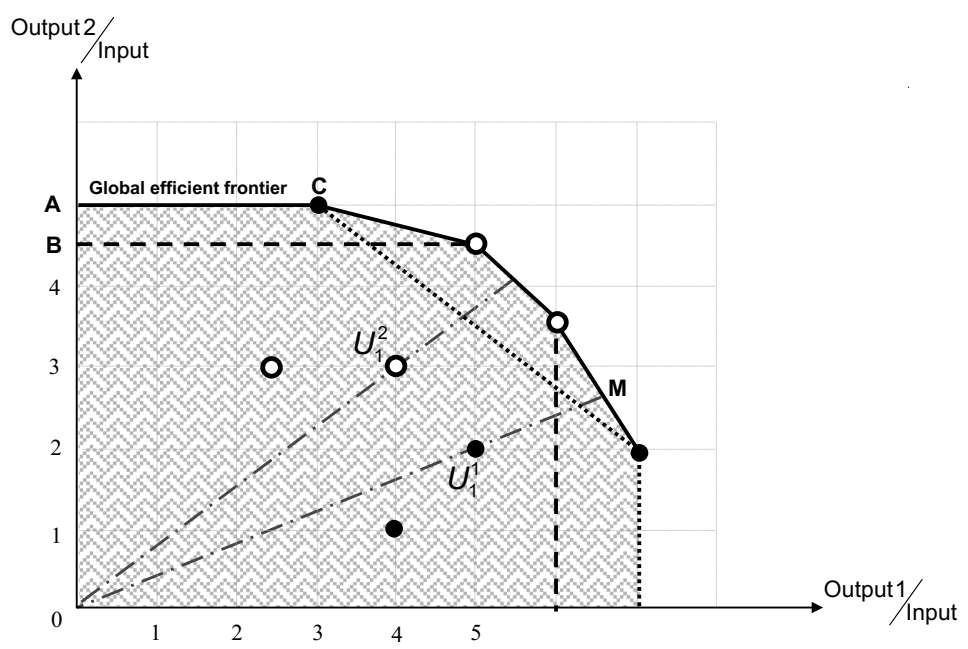

Fig. 3 The global Malmquist index measurement for unit 1

As can be seen in Figure 3, unit 1 in time period 1 and in time period 2 has been denoted by $U_{1}^{1}$ and $U_{1}^{2}$, respectively. According to the definition of the global Malmquist index in (8), the corresponding Malmquist index for this unit can be determined as follows:

$$
G M I=\frac{B_{C R S}^{G}\left(X_{1}^{2}, Y_{1}^{2}\right)}{B_{C R S}^{6}\left(X_{1}^{1}, Y_{1}^{1}\right)} \quad \text { where } \quad B_{C R S}^{6}\left(X_{1}^{2}, Y_{1}^{2}\right)=\frac{O U_{1}^{2}}{O K}, \quad B_{C R S}^{G}\left(X_{1}^{1}, Y_{1}^{1}\right)=\frac{O U_{1}^{1}}{O M}
$$

According to (15), considering the global technology, the efficiency of $U_{1}^{1}$ represented by $B_{C R S}^{6}\left(X_{1}^{1}, Y_{1}^{1}\right)$ is evaluated by $O U_{1}^{1} / O M$. This shows that in the determination of the global Malmquist index, $D_{C R S}^{6}\left(X_{1}^{1}, Y_{1}^{1}\right)$ uses the reference point $\mathrm{M}$, which is a linear combination of peer units $\mathrm{G}$ and $\mathrm{E}$ from different time periods, i.e. two observations among the most efficient units over time. However, 
as long as these two observations for some reasons (e.g. resulting from a rapid change in the characteristics of the technology over time) are considered non-homogeneous, reference point M may not be producible, meaning that the results become unreliable. This leads to the conclusion that such a global production possibility set is not an appropriate representation of the best practice technology which has really been experienced over time. In this case, an alternative aggregation of the contemporaneous technologies, which can avoid producing such virtual units in the global benchmark technology, is needed. In other words, a pure aggregation of what have really been observed has to be applied, whereby the role of each contemporaneous technology in the determination of the global benchmark technology is kept. This can be done by means of a safe definition which does not necessitate any further assumptions to be made for the aggregation of the experienced technologies, e.g. concerning the convex envelope of the technologies over time. This aggregation of the two technologies, which forms a new best practice technology, can be defined as follows:

$$
P P S_{C R S}^{O}=P P S_{C R S}^{1} \cup P P S_{C R S}^{2}
$$

where $P P S_{C R S}^{O}$ is the smallest aggregate (pure aggregation) technology set consisting of the two contemporaneous technologies, i.e. the minimum extrapolation principle is considered and as it will be shown in the next section that it also satisfies CRS. We shall refer to it as overall production possibility set or overall technology. Based on this definition, the overall technology ( $\left.P P S_{C R S}^{O}\right)$ is the shaded area bounded by ACIDEJGH in Figure 4.

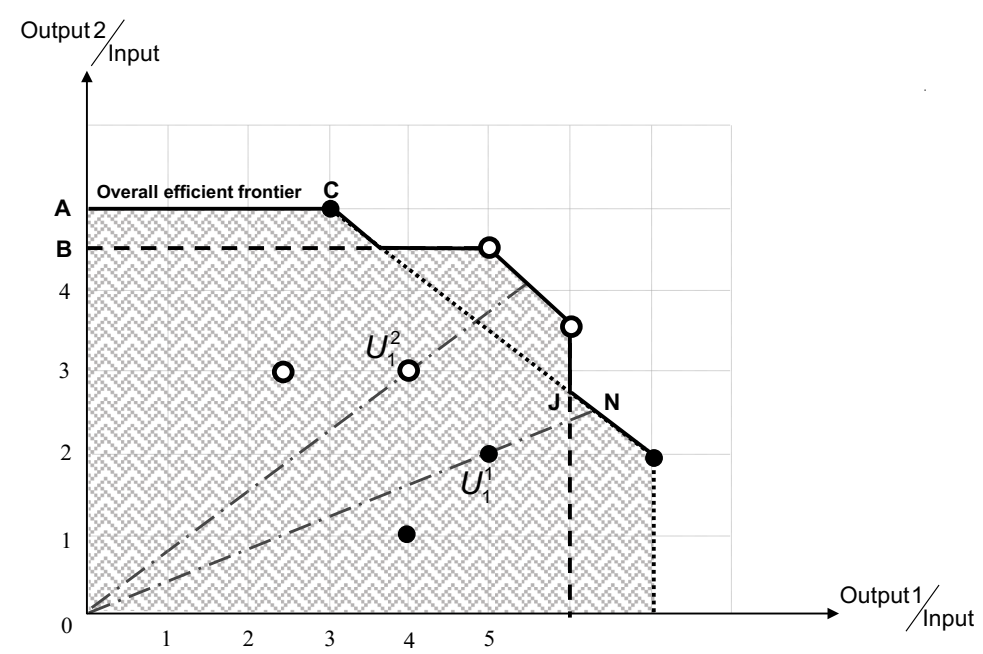

Fig. 4 The overall technology and its efficient frontier

On the basis of the depicted technology set, the proposed new Malmquist index -overall Malmquist index - for unit 1 can be determined as follows: 


$$
O M I=\frac{B_{C R S}^{\theta}\left(X_{1}^{2}, Y_{1}^{2}\right)}{B_{C R S}^{\theta}\left(X_{1}^{1}, Y_{1}^{1}\right)} \quad \text { where } \quad B_{C R S}^{\otimes}\left(X_{1}^{2}, Y_{1}^{2}\right)=\frac{O U_{1}^{2}}{O K}, \quad B_{C R S}^{\otimes}\left(X_{1}^{1}, Y_{1}^{1}\right)=\frac{O U_{1}^{1}}{O N}
$$

From (17) it is taken that, unlike in the global form in which $B_{C R S}^{6 / 6}\left(X_{1}^{1}, Y_{1}^{1}\right)$ applies the reference point $\mathrm{M}$, in the overall form, $B_{C R S}^{8}\left(X_{1}^{1}, Y_{1}^{1}\right)$ uses the reference point $\mathrm{N}$. This point is a linear combination of peer units $\mathrm{G}$ and $\mathrm{C}$, i.e. observations from the same contemporaneous technology. With respect to the assumption that technology remains constant between the start and the end of each time period and convexity holds between observations within each contemporaneous period, the produced reference point $\mathrm{N}$ will be feasible and acceptable. Likewise, for computing $B_{C R S}^{8}\left(X_{1}^{2}, Y_{1}^{2}\right)$ in the overall form, the reference point $\mathrm{K}$ has been suggested, which is a linear combination of peer units $\mathrm{E}$ and $\mathrm{D}$, i.e. observations from the other contemporaneous technology. In this particular case, $D_{C R S}^{8}\left(X_{1}^{2}, Y_{1}^{2}\right)$ and $B_{C R S}^{Q}\left(X_{1}^{2}, Y_{1}^{2}\right)$ use the same reference point $\mathrm{K}$, and the results provided by both the global and overall forms are the same.

\section{Formalization of the Overall Malmquist Index}

In the following, we formulate the overall Malmquist index illustrated graphically in the previous section. Theoretical aspects of the proposed index will also be described. Consider $n$ DMUs observed in time period $t(t=1, \ldots, T)$. Using the same notations for the level of inputs and outputs as well as the same assumptions for the time periods as introduced in Section 3, the contemporaneous technologies can be defined similarly. Motivated by the principal idea behind the determination of the global technology already mentioned in Sections 3 and 4, we assume that all observations from all periods are theoretically and potentially able to access a best practice technology which is formed from the experienced contemporaneous technologies over time (for a more detailed discussion, see also $\mathrm{Oh}$ and Lee 2010; Chen and Yang 2011). However, according to the discussions in the previous section, the overall best practice technology is obtained in a particular way which requires making the following assumptions:

- Observations in each contemporaneous time period operate under the same technology. It is supposed that the technology remains constant between the start and the end of each time period.

- Because of the change in the characteristics of the technology over time, a convex combination of observations from different time periods is not appropriate and thus not permitted.

Under these assumptions, the overall best practice technology can conceptually be represented by the overall production possibility set or overall technology as follows: 
$P P S^{O}=P P S_{C R S}^{1} \cup \ldots \cup P P S_{C R S}^{T}$

where $P P S^{O}$ is a pure aggregation of the experienced contemporaneous technologies. Although this representation is conceptually useful, a more precise model of the overall technology can be derived by considering a number of mathematical axioms as follows:

1. (Non-emptiness). The observed $\left(X_{j}^{t}, Y_{j}^{t}\right) \in P P S^{O}, t=1, \ldots, T ; j=1, \ldots, n$.

2. (Free disposability). If $(X, Y) \in P P S^{O}, X^{\prime} \geq X, Y^{\prime} \leq Y$, then $\left(X^{\prime}, Y^{\prime}\right) \in P P S^{O}$.

3. (Ray unboundedness). If $(X, Y) \in P P S^{O}$, then $(\alpha X, \alpha Y) \in P P S^{O}$ for all $\alpha \geq 0$.

4. (Local convexity). If $(X, Y)$ and $\left(X, Y / \rho \in P P S^{O}\right.$, then $\lambda(X, Y)+(1-\lambda)\left(X \%, \% / \rho \in P P S^{O}\right.$ for any $\lambda \in[0,1]$, provided that there exists $t(t=1, \ldots, T)$ such that both $(X, Y)$ and $\left(X /, Y / \varphi \in P P S_{C R S}^{t}\right.$.

5. (Minimum extrapolation). $P P S^{O}$ is the smallest set which satisfies axioms 1-4.

The following theorem not only confirms that the overall technology in (18) satisfies the above axioms but also provides a mathematical framework which is more useful from computational point of view.

Theorem 1: A technology set which satisfies axioms 1-5 is a pure aggregation of the contemporaneous technologies as follows:

$$
\begin{aligned}
P P S_{C R S}^{O}=\bigcup_{k=1}^{T} P P S_{C R S}^{k}=\left\{(X, Y) \in \mathfrak{R}_{+}^{m} \times \mathfrak{R}_{+}^{s} \mid\left(X \geq \sum_{j=1}^{n} \lambda_{j}^{1} x_{i j}^{1}, \quad Y \leq \sum_{j=1}^{n} \lambda_{j}^{1} y_{r j}^{1}\right) \text { or } \ldots\right. \\
\left.\quad \operatorname{or}\left(X \geq \sum_{j=1}^{n} \lambda_{j}^{T} x_{i j}^{T}, \quad Y \leq \sum_{j=1}^{n} \lambda_{j}^{T} y_{r j}^{T}\right) ; \quad \lambda_{j}^{k} \geq 0, \quad k, j=1, \ldots, T\right\}
\end{aligned}
$$

Proof: With respect to the definition of the contemporaneous technologies, it is straightforward. Note here that the third axiom explains why the global technology set in (19) has been denoted by a subscript "CRS".

According to this theorem, the output distance function can be defined as follows:

$$
B_{C R S}^{8}\left(X^{t}, Y^{t}\right)=\inf \left\{\beta:\left(X^{t}, Y^{t} / \beta\right) \in P P S_{C R S}^{O}\right\} \quad X^{t} \in R_{+}^{m}, \quad Y^{t} \in R_{+}^{s}, \quad t=1, \ldots, T
$$

Note that the definition of an input distance function can be given similarly. In the following, the analysis will be done on the basis of the output distance function in (20). It may straightforwardly be investigated for the input distance function. 
Based on Theorem 1, the mathematical formulation for the determination of the above distance function is straightforward. The corresponding distance function for $\operatorname{DMU} p(p=1, \ldots, n)$ can be computed by means of the following mixed integer linear programming problem:

$$
\left[B_{C R S}^{\theta}\left(X_{p}^{t}, Y_{p}^{t}\right)\right]^{-1}=\max \left\{\theta_{p}^{t} \mid \begin{array}{ll}
\sum_{j=1}^{n} \lambda_{j}^{k} x_{i j}^{k} \leq x_{i p}^{t}+M_{k} \chi_{k}, & i=1, \ldots, m, \quad k=1, \ldots, T ; \\
\sum_{j=1}^{n} \lambda_{j}^{k} y_{r j}^{k} \geq y_{r p}^{t} \theta_{p}^{t}-M_{k} \chi_{k}, \quad r=1, \ldots, s, \quad k=1, \ldots, T ; \\
\sum_{k=1}^{T} \chi_{k}=T-1, \quad \chi_{k} \in\{0,1\} ; \quad \lambda_{j}^{k} \geq 0 ; \quad \theta_{p}^{t} \text { free in sign }
\end{array}\right\}
$$

In this problem, there exist $T$ contemporaneous technologies whose related constraints have been incorporated in the model by means of $\chi_{k}(k=1, \ldots, T)$ as a set of auxiliary binary variables as well as sufficiently large constants $M_{k}(k=1, \ldots, T)$. These constraints define a set of either-or constraints in the problem by which the following relation can be identified:

$$
\left(X_{p}^{t}, \theta_{p}^{t} Y_{p}^{t}\right) \in P P S_{C R S}^{O} \Leftrightarrow\left(X_{p}^{t}, \theta_{p}^{t} Y_{p}^{t}\right) \in P P S_{C R S}^{1} \vee P P S_{C R S}^{2} \vee \ldots \vee P P S_{C R S}^{T}
$$

On this basis, one of the sets of the constraints related to the contemporaneous technologies has to be active at any time. This guarantees that the reference points of inefficient units are always producible from a set of observations operating under the same contemporaneous technology.

Considering (22), the problem of maximizing $\theta_{p}^{t}$ such that $\left(X_{p}^{t}, \theta_{p}^{t} Y_{p}^{t}\right) \in P P S_{C R S}^{O}$ is identical with finding the largest value among $\left\{\theta_{p 1}^{\imath^{*}}, \theta_{p 2}^{t^{*}}, \ldots, \theta_{p T}^{t^{*}}\right\}$ in which $\theta_{p k}^{t^{*}}(k=1, \ldots, T)$ can be computed by maximizing $\theta_{p k}^{t}$ such that $\left(X_{p}^{t}, \theta_{p k}^{t} Y_{p}^{t}\right) \in P P S_{C R S}^{t}(t=1, \ldots, T)$. Therefore, the objective function value of model (21) denoted by $\theta_{p}^{t^{*}}$ can be alternatively determined using an enumeration-based procedure by means of computing the optimal objective values in each contemporaneous technology (i.e. $\theta_{p k}^{t^{*}}$ ) separately and finding the largest one as follows:

$$
\theta_{p}^{t^{*}}=\max \left\{\max \left\{\begin{array}{l}
\left.\theta_{p k}^{t} \mid \begin{array}{ll}
\sum_{j=1}^{n} \lambda_{j}^{k} x_{i j}^{k} \leq x_{i p}^{t}, & i=1, \ldots, m, \\
\sum_{j=1}^{n} \lambda_{j}^{k} y_{r j}^{k} \geq y_{r p}^{t} \theta_{p k}^{t}, & r=1, \ldots, s, \\
\lambda_{j}^{k} \geq 0, \quad j=1, \ldots, n ; & \theta_{p k}^{t} \text { free in sign }
\end{array}\right\}, k=1, \ldots, T
\end{array}\right\}\right.
$$

where $\left[B_{C R S}^{\theta}\left(X_{p}^{t}, Y_{p}^{t}\right)\right]^{-1}=\theta_{p}^{t^{*}}$. (Enumeration-based procedures have also been used for different types of problems in the literature; see, e.g., Cherchye et al. 2001 for the FDH models). 
The straightforward corollary of the above discussion is that the proposed index does not need to be recomputed completely when a new time period is incorporated. In other words, it allows storing previous results to avoid recalculation and hence only the local optimal objective values resulting from the new observed technology have to be determined for including into the enumeration procedure. As a result, comparing to the global index, the overall index is less sensitive with respect to changes in the shape of the benchmark technology resulting from the new observations. This procedure also gives rise to the objective of investigating a linear programming reformulation of the problem. It was motivated by the fact that, apart from conceptual and computational interests, a linear programming formulation of the problem can give the possibility to identify the dual of the problem, which can also provide additional valuable managerial information.

Theorem 2. A linear programming (LP) problem that is equivalent to the previous mixed integer linear programming problem (MILP) is:

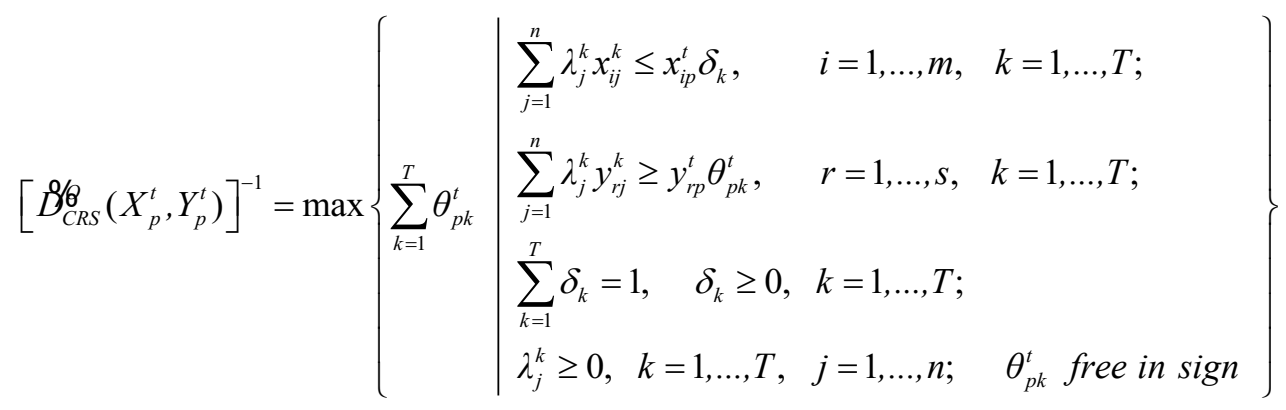

Proof. The structure of the proof is generally based on the procedure in transforming mixed integer linear programming problems to linear programming problems for FDH models which has first been proposed into the literature by Agrell and Tind (2001). According to the relation in (22), the mathematical model in (23) can be reformulated as:

$$
\left[B_{C R S}^{8}\left(X_{p}^{t}, Y_{p}^{t}\right)\right]^{-1}=\max \left\{\sum_{k=1}^{T} f_{p k}^{t}\left(\delta_{k}\right) \mid \sum_{k=1}^{T} \delta_{k}=1, \quad \delta_{k} \in\{0,1\}, k=1, \ldots, T\right\},
$$

where

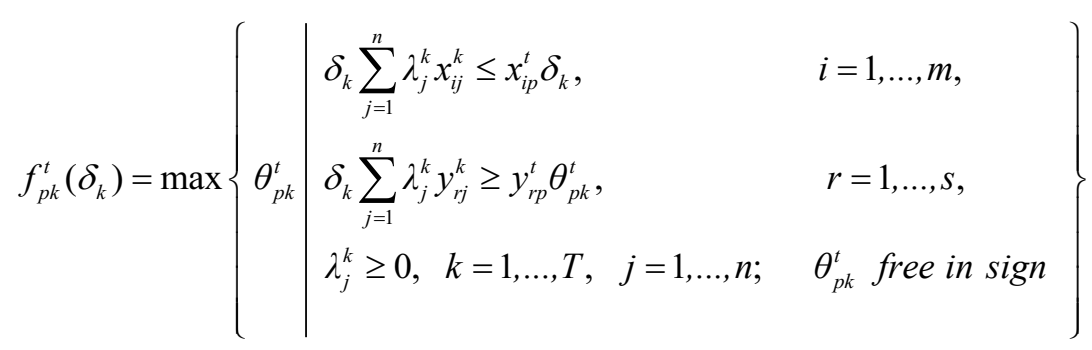

We can observe that the above function is homogeneous, i.e. $f_{p k}^{t}\left(\delta_{k}\right)=\delta_{k} f_{p k}^{t}(1)$. On this basis, (25) can be written as: 


$$
\left[\mathcal{B}_{C R S}^{\theta}\left(X_{p}^{t}, Y_{p}^{t}\right)\right]^{-1}=\max \left\{\sum_{k=1}^{T} \delta_{k} f_{p k}^{t}(1) \mid \sum_{k=1}^{T} \delta_{k}=1, \quad \delta_{k} \in\{0,1\}, k=1, \ldots, T\right\} .
$$

Obviously, the variable $\delta_{k}$ (even as non-negative variable) will be automatically one for the maximum $f_{p k}^{t}(1)$ and zero otherwise, i.e. the maximum of $\sum_{k=1}^{T} \delta_{k} f_{p k}^{t}(1)$ will occur at one of the endpoints of its domain not at an interior point. This implies that (27) is equivalent to:

$$
\left[B_{C R S}^{8}\left(X_{p}^{t}, Y_{p}^{t}\right)\right]^{-1}=\max \left\{\sum_{k=1}^{T} \delta_{k} f_{p k}^{t}(1) \mid \sum_{k=1}^{T} \delta_{k}=1, \quad \delta_{k} \geq 0, \quad k=1, \ldots, T\right\} .
$$

where $\delta_{k}(k=1, \ldots, T)$ have been transformed into non-negative variables. Consequently, according to (28), model (25) can be rewritten as:

$$
\left[B_{C R S}^{8}\left(X_{p}^{t}, Y_{p}^{t}\right)\right]^{-1}=\max \left\{\begin{array}{l|l}
\sum_{k=1}^{T} \theta_{p k}^{t} & \begin{array}{l}
\delta_{k} \sum_{j=1}^{n} \lambda_{j}^{k} x_{i j}^{k} \leq x_{i p}^{t} \delta_{k}, \\
\delta_{k} \sum_{j=1}^{n} \lambda_{j}^{k} y_{r j}^{k} \geq y_{r p}^{t} \theta_{p k}^{t}, \quad r=1, \ldots, s, \quad k=1, \ldots, T ; \\
\sum_{k=1}^{T} \delta_{k}=1, \quad \delta_{k} \geq 0, \quad k=1, \ldots, T ; \\
\lambda_{j}^{k} \geq 0, \quad k=1, \ldots, T, \quad j=1, \ldots, n ; \quad \theta_{p k}^{t} \text { free in sign }
\end{array}
\end{array}\right\}
$$

By defining $\delta_{k} \lambda_{j}^{k}=\bar{\lambda}_{j}^{k}(k=1, . ., T)$, we will obtain the linear programming based-model in (24).

Now, the overall Malmquist index is defined on $P P S_{C R S}^{O}$ as:

$$
M I_{C R S}^{O}\left(X_{p}^{t+1}, Y_{p}^{t+1}, X_{p}^{t}, Y_{p}^{t}\right)=\frac{B_{C R S}^{8}\left(X_{p}^{t+1}, Y_{p}^{t+1}\right)}{B_{C R S}^{8}\left(X_{p}^{t}, Y_{p}^{t}\right)}
$$

where one of the above-proposed models can be applied for determining $B_{C R S}^{Q}\left(X_{p}^{t}, Y_{p}^{t}\right)$ and $B_{C R S}^{\otimes}\left(X_{p}^{t+1}, Y_{p}^{t+1}\right)$, i.e. the computations of $B_{C R S}^{\otimes}\left(X_{p}^{t+1}, Y_{p}^{t+1}\right)$ is like $B_{C R S}^{\otimes}\left(X_{p}^{t}, Y_{p}^{t}\right)$ where $t$ is substituted by $t+1$ in the corresponding models. Furthermore, by considering

$$
\begin{aligned}
\text { Best Practice Change (BPC) } & =\left[\frac{B P G_{C R S}^{O, t+1}\left(X_{p}^{t+1}, Y_{p}^{t+1}\right)}{B P G_{C R S}^{O, t}\left(X_{p}^{t}, Y_{p}^{t}\right)}\right] \\
& =\left[\frac{B_{C R S}^{(}\left(X_{p}^{t+1}, Y_{p}^{t+1}\right)}{B_{C R S}^{t^{t+1}}\left(X_{p}^{t+1}, Y_{p}^{t+1}\right)} \times \frac{B_{C R S}^{6}\left(X_{p}^{t}, Y_{p}^{t}\right)}{B_{C R S}^{8}\left(X_{p}^{t}, Y_{p}^{t}\right)}\right]
\end{aligned}
$$

the overall Malmquist index can be represented by means of the following decomposition: 


$$
O M I=E C \times B P C
$$

The implication of (32) is that the change in productivity is affected by two components. The first component is EC, which is referred to as efficiency change over time. It captures the change in the technical efficiency of the unit under consideration between time periods $t$ and $t+1$ (see also (5) in Section 3). The second component is BPC, which is referred to as best practice gap change in contemporaneous frontiers relative to the overall frontier. In other words, it indicates whether the contemporaneous technology $t+1$ in the region this unit operates is closer to or farther away from the overall technology frontier than is the contemporaneous technology $t$. On this basis, if the value of the overall Malmquist index or any of its components is less than one, it denotes regress; a value greater than one implies progress, while a value of one indicates unchanged situation.

It has to be noted (but is not shown here) that the aforementioned decomposition can be extended with another important factor, which can capture the change in scale efficiency, e.g., by following the same structure as RD decomposition in Ray and Desli (1997). In this case, since the overall technology is obtained by the aggregation of the contemporaneous technologies, the proposed index will be immune to infeasibility for computing the corresponding components. Furthermore, the following theorems show the relation between the distance functions and the corresponding measures of the Malmquist index within the contemporaneous, global, and overall forms.

Theorem 3. For any $\left(X^{t}, Y^{t}\right)$ in a panel of $n$ DMUs observed in each time period $t(t=1, \ldots, T)$ we have

$$
B_{C R S}^{6}\left(X^{t}, Y^{t}\right) \leq B_{C R S}^{\otimes}\left(X^{t}, Y^{t}\right) \leq B_{C R S}^{6}\left(X^{t}, Y^{t}\right), \quad k=1, \ldots, T
$$

Proof. Reference to (23), clearly $B_{C R S}^{\otimes}\left(X^{t}, Y^{t}\right) \leq B_{C R S}^{6}\left(X^{t}, Y^{t}\right), k=1, \ldots, T$. Comparing the definitions of the global and overall technologies, we can see that $P P S_{C R S}^{O} \subseteq P P S_{C R S}^{G}$, which leads to $B_{C R S}^{6}\left(X^{t}, Y^{t}\right) \leq B_{C R S}^{8}\left(X^{t}, Y^{t}\right), t=1, \ldots, T$.

It has to be emphasized that there exists $k, k \in\{1, \ldots T\}$, such that $D_{C R S}^{\ominus}\left(X^{t}, Y^{t}\right)=B_{C R S}^{6}\left(X^{t}, Y^{t}\right)$. In addition, a sufficient condition for $B_{C R S}^{Q}\left(X^{t}, Y^{t}\right)=B_{C R S}^{Q}\left(X^{t}, Y^{t}\right)$ is that $P P S_{C R S}^{O}$ satisfies convexity. These give rise to the following theorems.

Theorem 4. A sufficient condition for equality of the overall and global Malmquist indices is the convexity of the overall technology.

Proof. According to the proof of Theorem 3 and the foregoing discussion, it is straightforward. 
On this basis, these two indices could tend to diverge when the overall technology exhibits areas violating convexity in its shape.

According to Althin (2001), technical change is Hicks neutral if any contemporaneous technology $s$ in the analysis can be obtained from another contemporaneous technology $t$ by means of a parallel shift. This means that the technology frontier can only shift inwards or outwards so that its curvature remains unchanged over time. This can also be translated into the following condition between the distance functions of the contemporaneous technologies $s$ and $t$ :

$$
B_{C R S}^{\circ}(X, Y)=F(s) B_{C R S}^{b}(X, Y), \quad t, s=1, \ldots, T
$$

where $F(s)$ is a function of $s$. (For a more detailed description about Hicks-neutral technical change, see also, e.g., Chambers and Färe 1994; Pastor and Lovell 2007).

Theorem 5. A sufficient condition for equality of the overall and contemporaneous Malmquist indices is Hicks-neutral technical change.

Proof. Consider the ratio of the overall Malmquist index to the contemporaneous Malmquist index between time periods $t$ and $t+1$ :

$$
\begin{aligned}
\frac{M I_{C R S}^{O}\left(X_{p}^{t+1}, Y_{p}^{t+1}, X_{p}^{t}, Y_{p}^{t}\right)}{M I_{C R S}\left(X_{p}^{t+1}, Y_{p}^{t+1}, X_{p}^{t}, Y_{p}^{t}\right)} & =\left\{\left(\frac{M I_{C R S}^{O}\left(X_{p}^{t+1}, Y_{p}^{t+1}, X_{p}^{t}, Y_{p}^{t}\right)}{M I_{C R S}^{t+1}\left(X_{p}^{t+1}, Y_{p}^{t+1}, X_{p}^{t}, Y_{p}^{t}\right)}\right) \times\left(\frac{M I_{C R S}^{O}\left(X_{p}^{t+1}, Y_{p}^{t+1}, X_{p}^{t}, Y_{p}^{t}\right)}{M I_{C R S}^{t}\left(X_{p}^{t+1}, Y_{p}^{t+1}, X_{p}^{t}, Y_{p}^{t}\right)}\right)\right\}^{\frac{1}{2}} \\
& =\left\{\left(\frac{B_{C R S}^{8}\left(X_{p}^{t+1}, Y_{p}^{t+1}\right) \times B_{C R S}^{6+1}\left(X_{p}^{t}, Y_{p}^{t}\right)}{B_{C R S}^{8}\left(X_{p}^{t}, Y_{p}^{t}\right) \times B_{C R S}^{6+1}\left(X_{p}^{t+1}, Y_{p}^{t+1}\right)}\right) \times\left(\frac{B_{C R S}^{6}\left(X_{p}^{t+1}, Y_{p}^{t+1}\right) \times B_{C R S}^{6}\left(X_{p}^{t}, Y_{p}^{t}\right)}{B_{C R S}^{6}\left(X_{p}^{t}, Y_{p}^{t}\right) \times B_{C R S}^{6}\left(X_{p}^{t+1}, Y_{p}^{t+1}\right)}\right)\right\}^{\frac{1}{2}}
\end{aligned}
$$

From the last equality, it is taken that $M I_{C R S}^{O}=M I_{C R S}$ if

$$
\frac{B_{C R S}^{Q}\left(X_{p}^{t+1}, Y_{p}^{t+1}\right) \times B_{C R S}^{6}\left(X_{p}^{t}, Y_{p}^{t}\right)}{B_{C R S}^{\otimes}\left(X_{p}^{t}, Y_{p}^{t}\right) \times B_{C R S}^{6}\left(X_{p}^{t+1}, Y_{p}^{t+1}\right)}=1 \quad s=t, t+1
$$

or equivalently:

$$
\frac{B_{C R S}^{6}\left(X_{p}^{t+1}, Y_{p}^{t+1}\right)}{B_{C R S}^{6}\left(X_{p}^{t}, Y_{p}^{t}\right)}=\frac{B_{C R S}^{6}\left(X_{p}^{t+1}, Y_{p}^{t+1}\right)}{B_{C R S}^{6}\left(X_{p}^{t}, Y_{p}^{t}\right)} \quad s=t, t+1
$$

Clearly, the above equalities hold if all contemporaneous technologies in the analysis coincide, i.e. since it obviously leads to $B_{C R S}^{\theta}\left(X_{p}, Y_{p}\right)=B_{C R S}^{6}\left(X_{p}, Y_{p}\right), s=1, \ldots, T$. Now let us assume that the technical change is Hicks neutral. Accordingly and with respect to the definition of the overall 
technology in (19), there exists $k, k \in\{1, \ldots, T\}$, such that $B_{C R S}^{8}(X, Y)=B_{C R S}^{6}(X, Y)$. Hence, the left hand side of (37) becomes $B_{C R S}^{8}\left(X_{p}^{t+1}, Y_{p}^{t+1}\right) / B_{C R S}^{8}\left(X_{p}^{t}, Y_{p}^{t}\right)=B_{C R S}^{6}\left(X_{p}^{t+1}, Y_{p}^{t+1}\right) / B_{C R S}^{6}\left(X_{p}^{t}, Y_{p}^{t}\right)$. Now according to (34), by transforming $B_{C R S}^{\circ}(X, Y), s=t, t+1$ as $B_{C R S}^{\circ}(X, Y)=F(s) B_{C R S}^{6}(X, Y), s=t, t+1$ on the right hand side of (37), the above equalities hold.

As mentioned earlier, the contemporaneous Malmquist index provides a measure of productivity change which fails circularity. In contrast to that, by means of the following theorem, we see that the proposed form of the Malmquist index satisfy circularity.

Theorem 6. The overall Malmquist index and its components are circular.

Proof. Since a single best practice technology is used, like any fixed base Malmquist index (see, e.g., Balk and Althin 1996), the overall Malmquist index and its components are circular.

\section{Illustrative Numerical Example}

In order to illustrate how the overall Malmquist index measures the productivity change over time and to compare it with the contemporaneous and global Malmquist indices, we analyze a panel of 73 commercial banks over the time period 2004-2009. These banks are located in 27 European countries (24 countries of the European Union plus Switzerland, Liechtenstein, and Norway). The data were collected from the banks' annual financial statements.

In the banking literature, productivity measurement and improvement using DEA have been addressed in many theoretical and application-oriented studies. An extensive literature review can be found, e.g., in Fethi and Pasiouras (2001) as well as in Paradi and Zhu (2013). They revealed that the so-called production approach has widely been used by researchers (Asmild et al. 2004). Within this approach, banks are considered as producers of products and services which use labor, capital, and other resources. According to this view and based on the data available, the number of employees, fixed assets and equity are specified as inputs, whereas loans, securitized financial assets, deposits and net commission income are used as outputs. Descriptive statistics of the three inputs and the four outputs over the time period 2004-2009 are given in Table 1 in the Appendix.

In order to obtain the contemporaneous technologies defined in (2), the entire period is divided into shorter time periods with the length of one year. This representation was motivated by the fact that all banks in each time period with the length of one year can be assumed to operate under the same technology (e.g. the same rules and regulations, competitive situation and economic condition). Furthermore, it is assumed that the technology remains constant between the start and the end of each year. This representation of the panel data is also well in line with the assumption that convex 
combinations of observations belonging to the same year are considered to be producible and thus feasible.

In the global form of the Malmquist index, the single best practice technology is obtained by the convex aggregation of all contemporaneous technologies. Hence, this framework implicitly assumes that convex combinations of observations across time periods (as virtual production units) are producible and feasible. However, we found that in our case this may not be a reasonable assumption because of improvements in the quality of services, changes in product ranges, and changes in economic regulations or restructuring, which is likely to make combinations of units from different time periods unrealistic. Therefore, the overall Malmquist index seems to be more appropriate.

The three forms of the Malmquist index and their components have been determined by the corresponding mathematical programming problems in Sections 3 and 5 which have been encoded in AIMMS, version 3.13. Table 2 summarizes the results, which are computed on average (calculated using a geometric mean) over the periods.

Table 2 Results obtained by the contemporaneous (Färe et al., 1994), global (Pastor and Lovell, 2005) and overall (this study) forms of the Malmquist index

\begin{tabular}{|c|c|c|c|c|c|c|c|}
\hline & $2004-2005$ & $2005-2006$ & $2006-2007$ & $2007-2008$ & 2008-2009 & $\begin{array}{l}\text { Cumulative } \\
\text { Productivity }\end{array}$ & 2004-2009 \\
\hline \multicolumn{8}{|c|}{ Contemporaneous Malmquist index } \\
\hline$M I_{C R S}^{t}$ & 1.079 & 1.063 & 1.062 & 1.068 & 0.952 & 1.238 & 1.140 \\
\hline$M I_{C R S}^{t+1}$ & 1.032 & 0.970 & 1.020 & 0.993 & 0.852 & 0.864 & 0.946 \\
\hline$M I_{C R S}$ & 1.055 & 1.016 & 1.041 & 1.030 & 0.901 & 1.034 & 1.038 \\
\hline$T C$ & 1.116 & 1.028 & 0.998 & 1.057 & 0.874 & 1.058 & 1.062 \\
\hline$E C$ & 0.946 & 0.988 & 1.043 & 0.974 & 1.030 & 0.978 & 0.978 \\
\hline \multicolumn{8}{|c|}{ Global Malmquist index } \\
\hline$M I_{C R S}^{G}$ & 1.037 & 1.016 & 1.047 & 1.033 & 0.904 & 1.029 & 1.029 \\
\hline$B P C$ & 1.096 & 1.028 & 1.004 & 1.061 & 0.878 & 1.053 & 1.053 \\
\hline$E C$ & 0.946 & 0.988 & 1.043 & 0.974 & 1.030 & 0.978 & 0.978 \\
\hline \multicolumn{8}{|c|}{ Overall Malmquist index } \\
\hline$M I_{C R S}^{O}$ & 1.032 & 1.007 & 1.046 & 1.027 & 0.913 & 1.019 & 1.019 \\
\hline$B P C$ & 1.091 & 1.019 & 1.003 & 1.054 & 0.886 & 1.042 & 1.042 \\
\hline$E C$ & 0.946 & 0.988 & 1.043 & 0.974 & 1.030 & 0.978 & 0.978 \\
\hline
\end{tabular}

As can be seen in Table 2, $M I_{C R S}^{O}$ (i.e. the overall Malmquist index) reports positive changes in the productivity during each of the first four adjacent periods, i.e. 3.2\% (2004-2005), 0.7\% (2005-2006), $4.6 \%$ (2006-2007) and 2.7\% (2007-2008), respectively. Subsequently, a sharp decline of productivity can be observed from 2008 to 2009 , i.e. $-8.7 \%$. This is the time period that encompasses the world financial crisis. The cumulative productivity in 2009 is $1.9 \%$ higher than in 2004 . Note here that $M I_{C R S}^{O}$ calculated using 2004 and 2009 data generates the same value, verifying that the overall Malmquist index is circular (see also the theoretical discussion in Section 5). The same interpretation about the 
circularity can also be given for the global form of the Malmquist index $\left(M I_{C R S}^{G}\right)$. Furthermore, the efficiency change (EC) and the best practice change (BPC) components in both the global and overall forms are also circular and cumulate to $-2.2 \%, 5.3 \%$ and $4.2 \%$, respectively.

Concerning the contemporaneous Malmquist index $\left(M I_{C R S}\right)$ reported in Table 2, the results are controversial. The cumulative productivity in 2009 is 3.4\% higher than in 2004 . However, computing $M I_{C R S}$ using 2004 and 2009 data provides a larger 3.8\% rise, verifying that the contemporaneous Malmquist index is not circular. As theoretically indicated in Section 3, the reason for this behavior is that the contemporaneous Malmquist index uses the geometric mean of two measures of productivity change (i.e. $M I_{C R S}^{t}$ and $M I_{C R S}^{t+1}$ ). The lack of circularity has been reflected in the frequently large differences between $M I_{C R S}^{t}$ and $M I_{C R S}^{t+1}$, represented in Table 2. This does not seem surprising since the technical change (TC) computed using the data in 2004 and 2009 (6.2\%) is different from cumulative productivity $(5.8 \%)$, which verifies that the technical change component is not circular either.

Results in Table 2 provide conclusive evidence that there are considerable differences between the overall Malmquist index and both the contemporaneous and the global forms of the Malmquist index. According to Theorem 5, the difference between the overall and contemporaneous forms of the Malmquist index verifies that the technical change was not Hicks neutral. In addition, discrepancies between the overall and global Malmquist indices can generally be explained by means of Theorem 4 which shows that the overall technology was not convex. In order to analyze in greater detail the difference between the global and overall Malmquist indices, the data have been aggregated for a set of 10 randomly selected banks over the entire period. Each of these banks is represented by its original unit number $\left(\mathrm{DMU}_{\#}\right)$. Table 3 summarizes the results of the overall and global Malmquist indices and the corresponding components.

Table 3 Results for 10 banks provided by the global (Pastor and Lovell, 2005) and overall (this study) Malmquist indices

\begin{tabular}{cccc|ccc}
\hline \multicolumn{3}{c|}{ Global Malmquist index } & \multicolumn{3}{c}{ Overall Malmquist index } \\
\hline Unit & $E C$ & $B P C$ & $G M I$ & $E C$ & $B P C$ & OMI \\
\hline $\mathrm{DMU}_{2}$ & 1.005 & 0.985 & 0.990 & 1.005 & 0.979 & 0.984 \\
$\mathrm{DMU}_{5}$ & 1.018 & 0.999 & 1.017 & 1.018 & 1.001 & 1.020 \\
$\mathrm{DMU}_{6}$ & 1.000 & 1.034 & 1.034 & 1.000 & 1.035 & 1.035 \\
$\mathrm{DMU}_{9}$ & 1.000 & 1.074 & 1.074 & 1.000 & 1.063 & 1.063 \\
$\mathrm{DMU}_{15}$ & 1.004 & 1.000 & 1.004 & 1.004 & 0.984 & 0.987 \\
$\mathrm{DMU}_{29}$ & 1.059 & 1.006 & 1.066 & 1.059 & 1.023 & 1.083 \\
$\mathrm{DMU}_{33}$ & 0.953 & 1.039 & 0.990 & 0.953 & 1.059 & 1.010 \\
$\mathrm{DMU}_{44}$ & 1.002 & 0.986 & 0.988 & 1.002 & 0.986 & 0.988 \\
$\mathrm{DMU}_{48}$ & 1.000 & 1.000 & 1.000 & 1.000 & 1.000 & 1.000 \\
$\mathrm{DMU}_{59}$ & 0.986 & 0.993 & 0.979 & 0.986 & 0.989 & 0.976 \\
\hline
\end{tabular}


As can be seen from Table 3, the results of the global Malmquist index differ substantially from the ones of the proposed index (cf. GMI and OMI). In Contrast - and in accordance with the theoretical arguments put forward in Section 5, efficiency change (EC) is identical in the two approaches. Therefore, the differences can be explained by comparing the results of the best practice change (BPC) in the global and overall frameworks. For some banks, the best practice changes for the global form are less than those for the overall form, while the opposite is true for some others. This can be explained by the different assumptions made about the aggregations of the observations over time in these two frameworks, whereby different shapes of the best practice technologies are determined (see also Theorem 4).

As an example, the results of the distance functions and the peer units which have been used for the determination of the Malmquist indices (i.e. $M I_{C R S}^{O}$ and $M I_{C R S}^{G}$ from $2005(t=2)$ to $2006(t=3)$ ), are analyzed. For the determination of the $M I_{C R S}^{O}$ and $M I_{C R S}^{G}$ of $\operatorname{DMU}_{p}$ ( $p$ : each of the above-selected banks), it is required to compute $B_{C R S}^{\beta}\left(X_{p}^{3}, Y_{p}^{3}\right) / B_{C R S}^{\beta}\left(X_{p}^{2}, Y_{p}^{2}\right)$ in the overall form and $B_{C R S}^{6}\left(X_{p}^{3}, Y_{p}^{3}\right) / B_{C R S}^{6}\left(X_{p}^{2}, Y_{p}^{2}\right)$ in the global form (see Sections 3 and 5). As reported in Table 4, the following comparison will be done between $B_{C R S}^{8}\left(X_{p}^{3}, Y_{p}^{3}\right)$ and $B_{C R S}^{6}\left(X_{p}^{3}, Y_{p}^{3}\right)$ only, but holds likewise between $B_{C R S}^{\theta}\left(X_{p}^{2}, Y_{p}^{2}\right)$ and $B_{C R S}^{G}\left(X_{p}^{2}, Y_{p}^{2}\right)$. Note here that $B_{C R S}^{\theta}\left(X_{p}^{3}, Y_{p}^{3}\right)$ and $B_{C R S}^{B}\left(X_{p}^{3}, Y_{p}^{3}\right)$ measure the efficiencies of each selected bank using 2006 data (i.e. time period 3) relative to the global and overall frontiers, respectively. Furthermore, each peer unit in time period $t(t=1, \ldots, 6)$ is denoted by $U_{p}^{t}$.

Table 4 Results of the comparison for the distance functions used in the global and overall frameworks

\begin{tabular}{|c|c|c|c|c|c|}
\hline $\begin{array}{l}\text { Distance } \\
\text { Function }\end{array}$ & Quantity & Peer Units & $\begin{array}{l}\text { Distance } \\
\text { Function }\end{array}$ & Quantity & Peer Units \\
\hline \multicolumn{3}{|c|}{ Global Malmquist index } & \multicolumn{3}{|c|}{ Overall Malmquist index } \\
\hline$D_{C R S}^{6}\left(X_{02}^{3}, Y_{02}^{3}\right)$ & 0.974 & $U_{22}^{3}, U_{02}^{4}, U_{04}^{5}, U_{22}^{5}$ & $B_{C R S}^{8}\left(X_{02}^{3}, Y_{02}^{3}\right)$ & 0.978 & $U_{02}^{4}, U_{04}^{4}, U_{11}^{4}, U_{22}^{4}$ \\
\hline$D_{C R S}^{6}\left(X_{05}^{3}, Y_{05}^{3}\right)$ & 0.957 & $U_{05}^{4}, U_{22}^{4}$ & $B_{C R S}^{8}\left(X_{05}^{3}, Y_{05}^{3}\right)$ & 0.957 & $U_{05}^{4}, U_{22}^{4}$ \\
\hline$D_{C R S}^{8}\left(X_{06}^{3}, Y_{06}^{3}\right)$ & 0.859 & $U_{21}^{3}, U_{04}^{4}, U_{22}^{4}, U_{60}^{4}, U_{68}^{6}$ & $B_{C R S}^{8}\left(X_{06}^{3}, Y_{06}^{3}\right)$ & 0.900 & $U_{04}^{4}, U_{11}^{4}, U_{21}^{4}, U_{22}^{4}, U_{60}^{4}$ \\
\hline$D_{C R S}^{6}\left(X_{09}^{3}, Y_{09}^{3}\right)$ & 0.816 & $U_{51}^{2}, U_{05}^{4}, U_{22}^{4}, U_{07}^{5}, U_{09}^{5}$ & $B_{C R S}^{8}\left(X_{09}^{3}, Y_{09}^{3}\right)$ & 0.833 & $U_{05}^{5}, U_{07}^{5}, U_{09}^{5}, U_{22}^{5}$ \\
\hline$D_{C R S}^{8}\left(X_{15}^{3}, Y_{15}^{3}\right)$ & 0.653 & $U_{07}^{2}, U_{05}^{4}, U_{07}^{5}$ & $B_{C R S}^{8}\left(X_{15}^{3}, Y_{15}^{3}\right)$ & 0.711 & $U_{05}^{5}, U_{07}^{5}, U_{68}^{5}$ \\
\hline$D_{C R S}^{6}\left(X_{29}^{3}, Y_{29}^{3}\right)$ & 0.690 & $U_{07}^{3}, U_{21}^{3}, U_{07}^{5}, U_{60}^{5}$ & $D_{C R S}^{8}\left(X_{29}^{3}, Y_{29}^{3}\right)$ & 0.706 & $U_{36}^{3}, U_{07}^{3}, U_{21}^{3}$ \\
\hline$D_{C R S}^{6}\left(X_{33}^{3}, Y_{33}^{3}\right)$ & 0.473 & $U_{21}^{3}, U_{60}^{4}, U_{04}^{5}, U_{07}^{5}, U_{68}^{6}$ & $D_{C R S}^{8}\left(X_{33}^{3}, Y_{33}^{3}\right)$ & 0.524 & $U_{04}^{4}, U_{05}^{4}, U_{07}^{4}$ \\
\hline$B_{C R S}^{8}\left(X_{44}^{3}, Y_{44}^{3}\right)$ & 0.639 & $U_{51}^{2}, U_{01}^{3}, U_{22}^{4}, U_{07}^{5}$ & $B_{C R S}^{8}\left(X_{44}^{3}, Y_{44}^{3}\right)$ & 0.658 & $U_{07}^{5}, U_{22}^{5}, U_{68}^{5}$ \\
\hline$D_{C R S}^{6}\left(X_{48}^{3}, Y_{48}^{3}\right)$ & 0.946 & $U_{48}^{2}, U_{48}^{4}, U_{48}^{5}, U_{48}^{6}$ & $B_{C R S}^{8 / 8}\left(X_{48}^{3}, Y_{48}^{3}\right)$ & 1.000 & $U_{48}^{3}$ \\
\hline$D_{C R S}^{g_{6}}\left(X_{59}^{3}, Y_{59}^{3}\right)$ & 0.534 & $U_{51}^{2}, U_{01}^{3}, U_{22}^{4}, U_{07}^{5}$ & $D_{C R S}^{8}\left(X_{59}^{3}, Y_{59}^{3}\right)$ & 0.545 & $U_{07}^{2}, U_{21}^{2}, U_{51}^{2}, U_{62}^{2}$ \\
\hline
\end{tabular}

In Table 4, the same results for the distance functions can be observed where peer units have been identical in the two approaches. An example can be seen for $B_{C R S}^{6}\left(X_{05}^{3}, Y_{05}^{3}\right)$ and $B_{C R S}^{6}\left(X_{05}^{3}, Y_{05}^{3}\right)$ in which the peer units provided in both the global and overall forms are $U_{05}^{4}$ and $U_{22}^{4}$. However, 
differences between the distance functions can be seen where peer units do not originate from the same contemporaneous technology.

In order to further investigate this case, e.g., we take a closer look at $B_{C R S}^{6}\left(X_{15}^{3}, Y_{15}^{3}\right)$. This distance function computes the efficiency of $\mathrm{DMU}_{15}$ from time period 3 in the global form of the Malmquist index. The obtained peer units for this bank have been suggested from different contemporaneous technologies, i.e. $\mathrm{DMU}_{07}$ from technology $2\left(U_{07}^{2}\right), \mathrm{DMU}_{05}$ from technology $4\left(U_{05}^{4}\right)$ and $\mathrm{DMU}_{07}$ from technology $5\left(U_{07}^{5}\right)$. Consequently, in the determination of the global Malmquist index, $B_{C R S}^{6 / 6}\left(X_{15}^{3}, Y_{15}^{3}\right)$ uses the reference point which is formed by a convex combination of $U_{07}^{2}, U_{05}^{4}$ and $U_{07}^{5}$. If these peer units are considered non-homogenous as they operate under different technologies, the corresponding reference point may not be producible and the results can be unreliable.

The overall form of the Malmquist index is immune to this problem. Considering $B_{C R S}^{8}\left(X_{15}^{3}, Y_{15}^{3}\right)$, we see that the peer units have been provided from the same contemporaneous technology, i.e. all from technology 5. More precisely, the reference point used in $B_{C R S}^{6}\left(X_{15}^{3}, Y_{15}^{3}\right)$ is formed by a convex combination of the peer units $U_{05}^{5}, U_{07}^{5}$ and $U_{68}^{5}$. The reason is that, within the overall framework, it has been assumed that the technology remains constant between the start and the end of each period and any convex combination of the observations has been considered to be feasible and acceptable.

\section{Conclusions and Outlook on Future Research}

In this paper, an alternative Malmquist-type index, the overall Malmquist index, has been proposed. The corresponding framework preserves the role of each experienced contemporaneous technology in the determination of the overall best practice technology, whereby an acceptable level of discrimination between non-homogeneous observations is provided. It has been shown that the proposed index possesses the circularity property, generates a single measure of productivity change and is immune to infeasibility under variable returns to scale. Furthermore, comparing to the global Malmquist index, the overall Malmquist index is less sensitive to changes in the shape of the benchmark technology when a new time period is incorporated. The suggested index and the corresponding theoretical features have also been studied numerically by means of analyzing a panel of commercial banks from European countries. The analysis has also explained reasons behind considerable differences between the results of the proposed index and both the contemporaneous and global forms of the Malmquist index.

All existing Malmquist indices in the literature have different properties and features. Hence, depending on a specific situation with certain assumptions, one can decide which index could be superior to the others, e.g., for modeling the best practice technology. In this study, according to some assumptions which are relevant in a series of practical cases, a new modeling of the best practice 
technology has been addressed, based on an innovative aggregation of the contemporaneous technologies. An interesting perspective for future research is to extend the proposed approach to deal with other types of the Malmquist index which use a similar aggregation in their nature such as the sequential Malmquist index (Shestalova 2003) and the meta-Malmquist index (Battese et al. 2004). Future research can also be concentrated on providing other decompositions of the proposed index. Examples are the three-way decomposition of Ray and Desli (1997) and the four-way decompositions of Simar and Wilson (1998) and Zofio and Lovell (1998). 


\section{Appendix}

Table 1 Descriptive statistics of the inputs and outputs used in this study

\begin{tabular}{|c|c|c|c|c|c|c|}
\hline & 2004 & 2005 & 2006 & 2007 & 2008 & 2009 \\
\hline \multicolumn{7}{|c|}{ Number of employees } \\
\hline Minimum & 23 & 42 & 143 & 194 & 236 & 236 \\
\hline Maximum & 135502 & 144900 & 152909 & 163126 & 197100 & 192000 \\
\hline Mean & 22857.588 & 24704.664 & 27080.178 & 29299.595 & 32317.845 & 30863.893 \\
\hline Standard Deviation & 33984.339 & 37260.813 & 40127.256 & 43456.410 & 48549.835 & 48203.344 \\
\hline \multicolumn{7}{|c|}{ Fixed assets } \\
\hline Minimum & 0.500 & 0.520 & 0.630 & 0.742 & 0.751 & 0.766 \\
\hline Maximum & 24296.034 & 27181.091 & 28537.099 & 27483.754 & 20523.705 & 22897.657 \\
\hline Mean & 1625.311 & 1804.939 & 1888.153 & 1997.389 & 1951.158 & 2162.238 \\
\hline Standard Deviation & 3462.298 & 3904.117 & 4186.226 & 4310.022 & 3822.564 & 4280.491 \\
\hline \multicolumn{7}{|c|}{ Equity } \\
\hline Minimum & 18.516 & 25.266 & 30.842 & 58.824 & 58.749 & 69.787 \\
\hline Maximum & 49573.654 & 55222.000 & 63266.000 & 70002.000 & 69000.000 & 80344.000 \\
\hline Mean & 6673.620 & 8354.265 & 9766.222 & 10769.354 & 10137.521 & 13085.763 \\
\hline Standard Deviation & 11076.431 & 13592.501 & 15355.725 & 17242.365 & 16251.591 & 20508.771 \\
\hline \multicolumn{7}{|c|}{ Loans } \\
\hline Minimum & 74.154 & 120.100 & 416.726 & 698.780 & 562.124 & 402.871 \\
\hline Maximum & 578362.606 & 709546.182 & 820184.486 & 1422770.625 & 1036075.283 & 919343.123 \\
\hline Mean & 80463.404 & 96333.449 & 112642.180 & 134512.417 & 131384.881 & 144394.564 \\
\hline Standard Deviation & 127608.589 & 151609.309 & 174324.554 & 231166.946 & 214103.933 & 227352.583 \\
\hline \multicolumn{7}{|c|}{ Financial assets } \\
\hline Minimum & 108.264 & 51.600 & 489.000 & 636.500 & 433.800 & 388.700 \\
\hline Maximum & 542773.371 & 659307.636 & 770728.540 & 1349900.284 & 918074.976 & 847826.477 \\
\hline Mean & 82553.063 & 98406.006 & 110827.476 & 129096.350 & 125893.872 & 130540.725 \\
\hline Standard Deviation & 131757.182 & 155563.933 & 173256.212 & 224212.681 & 195836.725 & 202463.471 \\
\hline \multicolumn{7}{|c|}{ Deposits } \\
\hline Minimum & 4.977 & 8.000 & 20.682 & 38.307 & 39.119 & 24.390 \\
\hline Maximum & 917508.411 & 1094078.237 & 1211121.280 & 1107058.839 & 1521360.405 & 1075996.000 \\
\hline Mean & 70334.173 & 100986.950 & 113863.105 & 129124.371 & 141351.977 & 113815.721 \\
\hline Standard Deviation & 162706.879 & 225768.514 & 251031.319 & 283131.458 & 323733.610 & 231074.730 \\
\hline \multicolumn{7}{|c|}{ Net commission income } \\
\hline Minimum & 3.052 & 3.380 & 7.029 & 8.178 & 9.321 & 8.318 \\
\hline Maximum & 11973.344 & 13769.270 & 15225.999 & 18457.553 & 15390.656 & 11920.048 \\
\hline Mean & 1272.973 & 1440.189 & 1709.549 & 1905.526 & 1713.393 & 1722.419 \\
\hline Standard Deviation & 2324.824 & 2657.320 & 3102.741 & 3449.835 & 2992.355 & 2954.023 \\
\hline
\end{tabular}

The amount of fixed assets, equity, loans, financial assets, deposits, and net commission income are given in thousand Euros. 


\section{References}

Aghdam, R.F. (2011). Dynamics of productivity change in the Australian electricity industry: Assessing the impacts of electricity reform. Energy Policy, 39, 3281-3295.

Agrell, P.J., \& Tind, J. (2001). A dual approach to nonconvex frontier models. Journal of Productivity Analysis, 16, 129-147.

Alirezaee, M.R., \& Afsharian, M. (2010). Improving discrimination of DEA models in multiple time periods evaluation. International Transactions in Operational Research, 17, 667-679.

Althin, R. (2001). Measurement of productivity changes: Two Malmquist index approaches. Journal of Productivity Analysis, 16, 107-128.

Aparicio, J., Pastor, J.T., \& Zofio, J.L. (2013). On the inconsistency of the Malmquist-Luenberger index. European Journal of Operational Research, 229, 738-742.

Asmild. M., Paradi, J.C., Aggarwall, V., \& Schaffnit, C. (2004). Combining DEA window analysis with the Malmquist index approach in a study of the Canadian banking industry. Journal of Productivity Analysis, 21, 67-89.

Balk, B.M., \& Althin, R. (1996). A new, transitive productivity index. Journal of Productivity Analysis, 7, 19-27.

Banker, R.D., Charnes, A., \& Cooper, W.W. (1984). Some models for estimating technical and scale inefficiency in Data Envelopment Analysis. Management Science, 31, 1078-1092.

Battese, G.E., Rao, D.S.P., \& Donnell, C.J. (2004). A metafrontier production function for estimation of technical efficiencies and technology gaps for firms operating under different technologies. Journal of Productivity Analysis, 21, 91-103.

Berg, S.A., Førsund, F.R., \& Jansen, E.S. (1992). Malmquist indexes of productivity growth during the deregulation of Norwegian banking 1980-1989. The Scandinavian Journal of Economics, 94, 211 228.

Camanho, A.S., \& Dyson, R.G. (2006). Data Envelopment Analysis and Malmquist indices for measuring group performance. Journal of Productivity Analysis, 26, 35-49.

Caves, D.W., Christensen, L.R,. \& Dievert, W.E. (1982). The economic theory of index number and the measurement of input output and productivity. Econometrica, 50, 1393-1414.

Chambers, R.G., Chung, Y., \& Färe, R. (1998). Profit, directional distance functions, and nerlovian efficiency. Journal of Optimization Theory and Applications, 98,351-364.

Chambers, R.G., \& Färe, R. (1994). Hicks' neutrality and trade biased growth: A taxonomy. Journal of Economic Theory, 64, 554-567.

Charnes, A., Clark, C.T., Cooper, W.W., \& Golany, B. (1985). A Developmental study of data envelopment analysis in measuring the efficiency of maintenance units in the U.S. air forces. Annals of Operations Research, 2, 95-112.

Charnes, A., Cooper, W.W., \& Rhodes, E. (1978). Measuring the efficiency of the decision making units. European Journal of Operational Research, 2, 429-444. 
Chen, K., \& Yang, H. (2011). A cross-country comparison of productivity growth using the generalised metafrontier Malmquist productivity index: With application to banking industries in Taiwan and China. Journal of Productivity Analysis, 35, 197-212.

Chen, Y. (2003). A Non-radial Malmquist productivity index with an illustrative application to Chinese major industries. International Journal of Production Economics, 83, 27-35.

Cherchye, L., Kuosmanen, T., \& Post, G.T. (2001). FDH directional distance functions with an application to European commercial banks. Journal of Productivity Analysis, 15, 201-215.

Chowdhury, H., Wodchis, W., \& Laporte, A. (2011). Efficiency and technological change in health care services in Ontario: An application of Malmquist productivity index with bootstrapping. International Journal of Productivity and Performance Management, 60, 721-745.

Chung, Y., Färe, R., \& Grosskopf, S. (1997). Productivity and undesirable outputs: A directional distance function approach. Journal of Environmental Management, 51, 229-240.

Corton, M.L., \& Berg, S.V. (2009). Benchmarking central American water utilities. Utilities Policy, $17,267-275$

Farrell, J.M. (1957). The measurement of productivity efficiency. Journal of the Royal Statistical Society, 120, 253-290.

Färe, R., Grosskopf, S., Lindgren, B., \& Roos, P. (1992). Productivity developments in Swedish Pharmacies: A non-parametric Malmquist approach. Journal of Productivity Analysis, 3, 85-101.

Färe, R., Grosskopf, S., Norris, M., \& Zhang, Z. (1994). Productivity growth technical progress and efficiency changes in industrialized countries. The American Economic Review, 84, 66-83.

Fethi, M.D., \& Pasiouras, F. (2010). Assessing bank efficiency and performance with operational research and artificial intelligence techniques: A survey. European Journal of Operational Research, 204, 189-198.

Fried, H.O., Lovell, C.A.K., \& Schmidt, S.S. (2008). The measurement of productive efficiency and productivity growth. Oxford University Press, New York.

Gilbert, R.A., \& Wilson, P. (1998). Effects of deregulation on the productivity of Korean banks. Journal of Economics and Business. 50, 133-155.

Gitto, S., \& Mancuso, P. (2012). Bootstrapping the Malmquist indexes for Italian airports. International Journal of Production Economics, 135, 403-411.

Grifell-Tatjé, E., \& Lovell, C.A.K. (1999). A Generalized Malmquist Productivity Index. TOP, 7, 81101.

Grifell-Tatjé, E., Lovell, C.A.K., \& Pastor, J.T. (1998). A quasi-Malmquist productivity index. Journal of Productivity Analysis, 10, 7-20.

Grosskopf , S. (2003). Some remarks on productivity and its decompositions. Journal of Productivity Analysis, 20, 459-474.

Hayami, Y. (1969). Sources of agricultural productivity gap among selected countries. American Journal of Agricultural Economics, 51, 564-575. 
Hayami, Y., \& Ruttan, V.W. (1970). Agricultural productivity differences among countries. The American Economic Review, 60, 895-911.

Hisali, E., \& Yawe, B. (2011). Total factor productivity growth in Uganda's telecommunications industry. Telecommunications Policy, 35, 12-19.

Kao, C. (2010). Malmquist productivity index based on common-weights DEA: The case of Taiwan forests after reorganization. Omega, 38, 484-491.

Kirigia, J.M., Emrouznejad, A., Cassoma, B., Asbu, E.Z., \& Barry, S. (2008). A performance assessment method for hospitals: The case of municipal hospitals in Angola. Journal of Medical Systems, 32, 509-519.

Lam, P., \& Shiu, A. (2010). Economic growth telecommunications development and productivity growth of the telecommunications sector: Evidence around the world. Telecommunications Policy, 34, 185-199.

Lovell, C.A.K. (2003). The decomposition of Malmquist productivity indexes. Journal of Productivity Analysis, 20, 437-458.

Malmquist, S. (1953). Index numbers and indifferent surfaces. Trabajos de Estadistica, 4, 209-242.

Nishimizu, M., \& Page, J.M. (1982). Total factor productivity growth, technological progress and technical efficiency change: Dimensions of productivity change in Yugoslavia, 1967-1978. The Economic Journal, 92, 920-936.

Oh, D.H. (2010). A global Malmquist-Luenberger productivity index. Journal of Productivity Analysis, 34, 183-197.

Oh D.H., \& Lee, J. (2010). A metafrontier approach for measuring Malmquist productivity index. Empirical Economics, 38, 47-64.

Paradi, J.C., \& Zhu, H. (2013). A survey on bank branch efficiency and performance research with Data Envelopment Analysis. Omega, 41, 61-79.

Pastor, J.T., Asmild, M., \& Lovell, C.A.K (2011). The biennial Malmquist productivity change index. Socio-Economic Planning Sciences, 45, 210-15.

Pastor, J.T., \& Lovell, C.A.K. (2005). A global Malmquist productivity index. Economics Letters, 88, 266-271.

Pastor, J.T., \& Lovell C.A.K. (2007). Circularity of the Malmquist productivity index. Economic Theory, 33, 591-599.

Pires, H.M., \& Fernandes, E. (2012). Malmquist financial efficiency analysis for airlines. Transportation Research Part E, 48, 1049-1055.

Podinovski, V.V. (2004). Production trade-offs and weight restrictions in data envelopment analysis. Journal of the Operational Research Society, 55, 1311-1322.

Podinovski, V.V. (2005). Selective convexity in DEA models. European Journal of Operational Research, 2, 552-563.

Portela, M.C.A.S., \& Thanassoulis, E. (2008). A circular Malmquist-type index for measuring productivity. Working Paper RP08-02. Aston University Birmingham B47ET, UK. 
Portela, M.C.A.S., \& Thanassoulis, E. (2010). Malmquist-type indices in the presence of negative data: An application to bank branches. Journal of Banking \& Finance, 34, 1472-1483.

Portela, M.C.A.S., Thanassoulis, E., Horncastle, A., \& Maugg, T. (2011). Productivity change in the water industry in England and Wales: Application of the meta-Malmquist index. Journal of the Operational Research Society, 62, 2173-2188.

Portela, M.C.A.S., Thanassoulis, E., \& Simpson, G. (2004). Negative data in DEA: A directional distance approach applied to bank branches. Journal of the Operational Research Society, 55, 11111121.

Ray, S.C., \& Desli, E. (1997). Productivity growth, technical progress and efficiency change in industrialized countries: Comment. The American Economic Review, 87, 1033-1039.

Shephard, R.W. (1970). Theory of cost and production function. Princeton University Press, Princeton.

Shestalova, V. (2003). Sequential Malmquist indices of productivity growth: An application to OECD industrial activities. Journal of Productivity Analysis, 19, 211-226.

Simar, L., \& Wilson, P.W. (1998). Productivity growth in industrialized countries. Working Paper, Department of Economics, University of Texas, Austin TX 78712.

Tovar. B., Ramos-Real, F.J., \& Fagundes, de Almeida E. (2011). Firm size and productivity: Evidence from the electricity distribution industry in Brazil. Energy Policy, 39, 826-833.

Tulkens, H., \& Malnero, A. (1994). Nonparametric approaches to the assessment of the relative efficiency of bank branches. CORE Discussion Paper 9447, Université Catholique de Louvain, Center for Operations Research \& Econometrics, Belgium.

Wang, C., Lee, J., \& Chang, Y. (2012). Measuring productivity in the biotechnology industry using the global Malmquist index. Applied Economics Letters, 19, 807-812.

Wheelock, D.C., \& Wilson, P. (1999). Technical progress, inefficiency and productivity change in U.S. banking 1984-1993. Journal of Money, Credit and Banking, 31, 212-234.

$\mathrm{Xu}, \mathrm{L}$. (2012). Theoretical and empirical studies of productivity growth in the agricultural economics: Cases of China and the United States. Physics Procedia, 24, 1475-1481.

Zofio, J.L. (2007). Malmquist productivity index decompositions: A unifying framework. Applied Economics, 39, 2371-2387.

Zofio, J.L., \& Lovell, C.A.K. (1998). Yet another Malmquist productivity index decomposition. Working Paper, Department of Economics, University of Georgia, Athens, GA 30602, USA.

Zofio, J.L., \& Lovell, C.A.K. (2001). Graph efficiency and productivity measures: An application to US agriculture. Applied Economics, 33, 1433-1442. 